\title{
Comparative Efficacy of Dual and Single Initiation of Add-On Oral Antihyperglycemic Agents in Type 2 Diabetes Uncontrolled on Metformin Alone: A Systematic Literature Review and Network Meta- Analysis
}

\author{
Dominik Lautsch • Adnan Alsumali • Euan McLeod • Yuting Kuang · Jing He • Rajpal Singh • \\ Arianna Nevo $\cdot$ Urs Arnet · Jennifer Uyei · Swapnil Rajpathak
}

Received: October 20, 2020 / Accepted: November 19, 2020 / Published online: December 12, 2020

(C) The Author(s) 2020

\begin{abstract}
Introduction: Current guidelines recommend adding an oral antihyperglycemic agent (AHA) to metformin in patients with type 2 diabetes mellitus (T2DM) uncontrolled on metformin. Recent randomized clinical trials (RCTs) have demonstrated that adding dual AHAs instead of a single AHA provided more effective glycemic control. However, the comparative efficacy of approved single and dual initiation strategies is unknown. Therefore, we conducted a Bayesian network meta-analysis to compare the efficacy of dual and single add-on oral AHAs in patients uncontrolled on metformin.
\end{abstract}

Supplementary Information The online version of this article (https://doi.org/10.1007/s13300-020-00975y) contains supplementary material, which is available to authorized users.

D. Lautsch $(\varangle) \cdot$ A. Alsumali · U. Arnet

S. Rajpathak

Merck Sharp \& Dohme Corp., a subsidiary of Merck

$\&$ Co., Inc., Kenilworth, NJ, USA

e-mail: dominik.lautsch@merck.com

E. McLeod

Pfizer, Inc., Tadworth, UK

Y. Kuang $\cdot$ J. He $\cdot$ A. Nevo $\cdot$ J. Uyei

IQVIA, Inc., San Francisco, CA, USA

R. Singh

IQVIA, Inc., Mumbai, India
Methods: A systematic literature review of RCTs was conducted following Cochrane and ISPOR guidelines. MEDLINE, Embase, and CENTRAL were searched from inception to November 19, 2019. Approved oral doses of sodium-glucose co-transporter-2 (SGLT-2) inhibitors, dipeptidyl peptidase-4 (DPP-4) inhibitors, and glucagonlike peptide-1 (GLP-1) receptor agonists in single or dual initiation therapies were indirectly compared. Outcomes focused on efficacy and included mean change from baseline in hemoglobin A1c (HbA1c), weight, systolic blood pressure (SBP), diastolic blood pressure, and achieving HbA1c target $<7 \%$ at 24-26 weeks. Fixed and random effects models with Markov chain Monte Carlo simulations were used.

Results: Of 1955 unique records screened, 25 RCTs $(14,264$ participants) were included. In patients uncontrolled on metformin, dual AHA added to metformin had statistically significant or a trend of greater reduction in HbA1c compared to single AHAs, with ertugliflozin + sitagliptin showing the greatest improvement. Statistically significant reductions in weight and SBP were observed with ertugliflozin + sitagliptin, ertugliflozin, or canagliflozin compared to single initiation DPP-4 inhibitors.

Conclusion: For reduction of HbA1c, weight, and SBP in patients uncontrolled on metformin, add-on dual AHAs showed greater improvement compared to single AHAs. These findings can further inform the treatment of T2DM patients uncontrolled on metformin. 
Keywords: Dual initiation; Network metaanalysis; Oral antihyperglycemic agent; Type 2 diabetes

\section{Key Summary Points}

Recent randomized clinical trials (RCTs) have demonstrated that adding dual antihyperglycemic agents (AHAs) instead of a single AHA to metformin provided more effective glycemic control. However, the comparative efficacy of dual and single initiation of approved oral sodiumglucose co-transporter-2 (SGLT-2) inhibitors, dipeptidyl peptidase-4 (DPP-4), and glucagon-like peptide-1 (GLP-1) receptor agonists for type 2 diabetes mellitus (T2DM) is unknown, and no head-to-head trials exist.

The aim of this research was to understand the efficacy of approved oral AHAs at 24-26 weeks in patients with T2DM uncontrolled on metformin by conducting a systematic literature review and Bayesian network meta-analysis.

Dual initiation therapies were to be consistently more effective in lowering HbA1c levels compared to placebo and single initiation therapies, particularly with ertugliflozin + sitagliptin dual initiation therapy.

Most dual initiation therapies, single initiation oral GLP-1 receptor agonists, and SGLT-2 inhibitors were significantly better in lowering body weight and SBP compared to single initiation DPP-4 inhibitors.

Clinicians can consider dual initiation strategies as viable alternative for T2DM patients uncontrolled on metformin alone.

\section{DIGITAL FEATURES}

This article is published with digital features, including a summary slide, to facilitate understanding of the article. To view digital features for this article go to https://doi.org/10.6084/ m9.figshare.13252250.

\section{INTRODUCTION}

Effective clinical management of type 2 diabetes mellitus (T2DM) requires an optimized treatment strategy to ensure adequate glycemic control and reduce diabetic complications [1]. Due to the progressive nature of T2DM, the standard first-line metformin monotherapy often becomes insufficient in achieving glycemic control, necessitating the use of additional therapy. The UK Prospective Diabetes Study (UKPDS) reported that almost 50\% of newly diagnosed patients using monotherapy require the addition of a second drug after 3 years and $75 \%$ of patients need additional agents by 9 years [2]. The 2020 American Diabetes Association (ADA) Standards of Care has recommended the addition of oral agents to metformin if the hemoglobin A1c (HbA1c) target is not achieved after approximately 3 months of metformin monotherapy [3]. Besides frequent monitoring of $\mathrm{HbA} 1 \mathrm{c}$ as recommended by clinical practice guidelines [4, 5], published evidence suggests that patients with an early intensification program had significantly shorter time to attain HbA1c goals compared to those who did not undergo early treatment intensification [6, 7].

Currently, many multiple oral antihyperglycemic agents (AHA) are prescribed for patients uncontrolled on metformin monotherapy, including sodium-glucose cotransporter-2 (SGLT-2) inhibitors, dipeptidyl peptidase-4 (DPP-4) inhibitors, glucagon-like peptide-1 (GLP-1) receptor agonists, thiazolidinediones, and sulfonylureas. A suitable combination therapy could potentially improve HbA1c control without hypoglycemia, promote weight control, and provide additional benefits through complementary mechanisms of actions, such as cardiovascular benefits 
associated with SGLT-2 inhibitors. While the use of sulfonylurea or thiazolidine is not ideal because of its association with increased body weight and hypoglycemia, combination therapies with the other classes are often considered based on the patient needs and risk factors [3].

Despite the need for additional treatment strategies for T2DM patients who fail on metformin monotherapy, a paucity of RCTs assessing head-to-head comparisons between dual or single initiation therapies remains. Previous network meta-analyses (NMA) have compared mostly single initiation therapies individually $[8,9]$ or as treatment classes [10] in patients uncontrolled on metformin alone, but there was no comparison between dual and single initiation therapies. In this regard, with the recent advances in oral AHA available for this population, an NMA including both dual and single initiation therapies can provide a statistical framework to evaluate multiple direct or indirect comparisons across these therapies as add-on to metformin and to support clinical decisions based on the comparative efficacy of these treatment options.

Therefore, a Bayesian NMA was conducted on the basis of a comprehensive systematic literature review (SLR), with the overarching aim to evaluate the comparative efficacy of single and dual initiated approved oral doses of SGLT2 inhibitors, DPP-4 inhibitors, and GLP-1 receptor agonist (all in combination with metformin) at 24-26 weeks in adult T2DM patients uncontrolled on metformin in RCTs.

\section{METHODS}

An SLR of published literature was conducted for this research, and a Bayesian NMA was used to synthesize the evidence. This article is based on previously conducted studies and does not contain any new studies with human participants or animals performed by any of the authors. A pre-specified protocol was developed prior to the conduct of the research. However, the systematic review was not registered in PROSPERO or other public registry platforms.

\section{Data Sources and Searches}

This study was performed as per a prespecified protocol in accordance with the Cochrane and International Society for Pharmacoeconomics and Outcomes Research (ISPOR) guidelines for conducting and reporting SLRs and NMAs [11-13]. The PRISMA checklist can be found in Supplementary Appendix Table 1. The OVID ${ }^{\circledR}$ SP platform was used to conduct searches in the Excerpta Medica Database (Embase), Medical Literature Analysis and Retrieval System Online $\left(\right.$ MEDLINE $^{\circledR}$ ) and Cochrane (via Evidence-Based Medicine [EBM]) on November 2019 for English-language RCTs reporting outcomes at 24-26 weeks of follow-up (see Supplementary Appendix Table 2 for full search strategy). In addition, registries (ClinicalTrials.gov and the European Union's Clinical Trials Register portals) were also accessed for missing variables and to ensure all relevant trials were identified. Clinical study reports for the VERTIS FACTORIAL, VERTIS MET, and VERTIS SU trials were provided by Merck Sharp \& Dohme Corp. and used supplementary data sources to the corresponding trial publications.

Publications identified through the systematic review process were evaluated in a stepwise process to assess whether they should be included for data extraction. Citations identified from the literature database searches were managed using the standard reference management software EndNote (X8), and DistillerSR was used to manage the screening process.

\section{Study Selection}

During the review process, the Patient population, Interventions, Comparators, Outcomes, Time and Study design (PICOTS) criteria were used for assessment of inclusion or exclusion of the studies in the NMA (Table 1). In brief, the SLR included RCTs on adults (age $\geq 18$ years) with T2DM and uncontrolled HbA1c (HbA1c $>7.0 \%)$ while on metformin, who were administered any of the approved oral doses of SGLT-2 inhibitors, DPP-4 inhibitors, and GLP-1 receptor agonists, as single or dual initiation therapies adjunctive to metformin. Eligible 
Table 1 PICOTS for the systematics literature review

\begin{tabular}{|c|c|}
\hline Criterion & Description \\
\hline Patient population & $\begin{array}{l}\text { T2DM (adults, } \geq 18 \text { years), } \\
\text { uncontolled HbA1c } \\
\text { (HbA1c }>7.0 \% \text { ), being } \\
\text { managed with metformin }\end{array}$ \\
\hline \multirow[t]{5}{*}{ Interventions } & $\begin{array}{l}\text { Approved doses of the } \\
\text { following oral therapies and } \\
\text { their combinations (dose } \\
\text { reported as once daily if not } \\
\text { otherwise specified): }\end{array}$ \\
\hline & $\begin{array}{l}\text { Metformin + SGLT-2i } \\
\text { (ertugliflozin } 5 \mathrm{mg} / 15 \mathrm{mg}, \\
\text { canagliflozin } 100 \mathrm{mg} / 300 \mathrm{mg} \text {, } \\
\text { dapagliflozin } 5 \mathrm{mg} / 10 \mathrm{mg}, \\
\text { empagliflozin } 10 \mathrm{mg} / 25 \mathrm{mg} \text { ) }\end{array}$ \\
\hline & $\begin{array}{l}\text { Metformin + DPP-4i } \\
\text { (saxagliptin } 2.5 \mathrm{mg} / 5 \mathrm{mg} \text {, } \\
\text { linagliptin } 5 \mathrm{mg} \text {, alogliptin } \\
25 \mathrm{mg} \text {, sitagliptin } 100 \mathrm{mg} \text {, } \\
\text { vildagliptin } 50 \mathrm{mg} \text { twice per } \\
\text { day) }\end{array}$ \\
\hline & $\begin{array}{l}\text { Metformin + DPP- } \\
\text { 4i + SGLT-2i (DPP-4i: } \\
\text { saxagliptin } 2.5 \mathrm{mg} / 5 \mathrm{mg}, \\
\text { linagliptin } 5 \mathrm{mg} \text {, alogliptin, } \\
\text { vildagliptin, sitagliptin } \\
100 \mathrm{mg} \text {; SGLT-2i: } \\
\text { ertugliflozin } 5 \mathrm{mg} / 15 \mathrm{mg}, \\
\text { canagliflozin } 100 \mathrm{mg} / 300 \mathrm{mg} \text {, } \\
\text { dapagliflozin } 5 \mathrm{mg} / 10 \mathrm{mg}, \\
\text { empagliflozin } 10 \mathrm{mg} / 25 \mathrm{mg})\end{array}$ \\
\hline & $\begin{array}{c}\text { Metformin + oral GLP-1 RA } \\
\text { (semaglutide } 7 \mathrm{mg} / 14 \mathrm{mg} \text { ) }\end{array}$ \\
\hline Comparators & $\begin{array}{l}\text { Same as interventions, and } \\
\text { metformin }+ \text { placebo } \\
\text { (dosing studies that only } \\
\text { included metformin were } \\
\text { excluded) }\end{array}$ \\
\hline
\end{tabular}

Table 1 continued

\begin{tabular}{|c|c|}
\hline Criterion & Description \\
\hline Outcomes & $\begin{array}{l}\text { Continuous outcomes- } \\
\text { Changes in HbAlc }(\%) \text {, } \\
\text { weight }(\mathrm{kg}), \mathrm{SBP}(\mathrm{mmHg}) \text {, } \\
\text { DBP }(\mathrm{mmHg}) \\
\text { Binary outcomes-HbAlc } \\
\text { within target range } \\
\text { (exploratory outcome: } \\
\text { expected range defined as: } \\
\text { HbAlc }<7.0 \%)\end{array}$ \\
\hline Time & No date restriction \\
\hline Study design & $\mathrm{RCT}$ \\
\hline Restrictions & $\begin{array}{l}\text { Trial duration: Outcomes } \\
\text { reported at } 24 \pm 2 \text { weeks } \\
\text { (trials longer than } 24 \text { weeks } \\
\text { were reviewed to capture any } \\
\text { interim reporting at the } 24 \text { to } \\
\text { 26-week target timeframe) } \\
\text { Language: English } \\
\text { Country: any }\end{array}$ \\
\hline $\begin{array}{l}\text { Exclusions in addition } \\
\text { to not meeting } \\
\text { PICOTS criteria }\end{array}$ & $\begin{array}{l}\text { Patients receiving insulin at } \\
\text { study entry } \\
\text { Insulin as a comparator } \\
\text { treatment } \\
\text { Non-human } \\
\text { Type } 1 \text { diabetes } \\
\text { Children (age }<18 \text { years) }\end{array}$ \\
\hline
\end{tabular}

$D B P$ diastolic blood pressure, DPP-4i dipeptidyl peptidase-4 inhibitor, GLP-1 RA glucagon-like peptide-1 receptor agonist, $H b A 1 c$ glycated hemoglobin, $R C T$ randomized clinical trial, $S B P$ systolic blood pressure, $S G L T$ $2 i$ sodium-glucose co-transporter 2 inhibitor 
comparators were the above interventions of interest or placebo adjunctive to metformin. All types of RCTs were considered if meeting PICOTS eligibility criteria, including both twoand multi-arm studies. Studies evaluating injectable AHA, insulin, diet, and exercise interventions were excluded. Efficacy outcomes included change from baseline in HbA1c, weight, systolic blood pressure (SBP), diastolic blood pressure (DBP), and proportion of patients achieving HbA1c $<7 \%$ at 24-26 weeks of follow-up.

All retrieved publications were initially reviewed based on abstract and title against the pre-defined eligibility criteria (PICOTS) by two reviewers. Publications included after title and abstract review were screened based on the full text by two reviewers. Uncertainty pertaining to inclusion of any study during the abstract and full-text screening steps was resolved either through reconciliation between the two reviewers or by majority consensus after consulting with a third reviewer. All studies included after the completion of full-text reviews were retained for quality assessment and data extraction.

\section{Data Extraction and Quality Assessment}

A data extraction template was developed to capture the evidence, and data were extracted for each study based on the outcome measures defined in the PICOTS criteria (Table 1). Data were extracted by one reviewer and reassessed by a second reviewer to ensure quality and completeness. Outcomes used in the NMA were extracted by two independent researchers and then reconciled.

The Revised Cochrane Risk of Bias Tool for Randomized Trials (RoB2) was used to perform quality assessment of individual studies [14].

\section{Data Synthesis and Analysis}

The feasibility of conducting an NMA was assessed by evaluating the formation of treatment networks across included studies and by recognizing any differences in patients or study design characteristics that are potential modifiers of treatment effects. The NMA feasibility assessment was performed on all outcomes of interest as per the PICOTS criteria. Standard errors were missing for three studies in weight and two studies in blood pressure outcomes. Data were imputed following the Cochrane Handbook [11]. In all cases, values were imputed by borrowing the standard error from a similar group (same treatment and similar baseline characteristics) from a different trial.

A Bayesian NMA was conducted, and the models were based on those presented in the National Institute of Health and Care Excellence (NICE) Decision Support Unit (DSU) Technical Support Document (TSD) 2 [15]. The evidence was synthesized using OPENBUGS version 3.2.3 via $\mathrm{R}$ Studio for both fixed effects (FE) and random effects (RE) Bayesian NMA models. Fitness of FE and RE models was evaluated individually for each outcome, as indicated by the deviance information criteria (DIC) values. For each outcome, the model with a lower DIC value was selected [16]. In cases where DIC was lower for the RE model compared with the FE model, the RE model was selected for enhanced rigor. Posterior densities for the unknown parameters were estimated using Markov chain Monte Carlo (MCMC) simulations. The analyses were based on 60,000 iterations on two chains, with a burn-in of at least 20,000 iterations. An identity link model was used for continuous outcomes (e.g., change in HbA1c from baseline) while Logit link with binomial likelihood distribution was used for binary outcomes (e.g., proportion of patients with HbA1c within target range). Non-informative prior distributions of relative treatment effects were used for all outcomes of interest, per published expert guidelines.

Trial-level data were used rather than individual-level data. For binary outcome(s), the pairwise odds ratios for each pair of comparisons and the absolute treatment effects for each intervention are presented. For continuous outcomes, the mean differences between each pair of treatments and the mean change from baseline for each intervention are presented. NMA results are presented as the posterior median of mean difference for continuous 


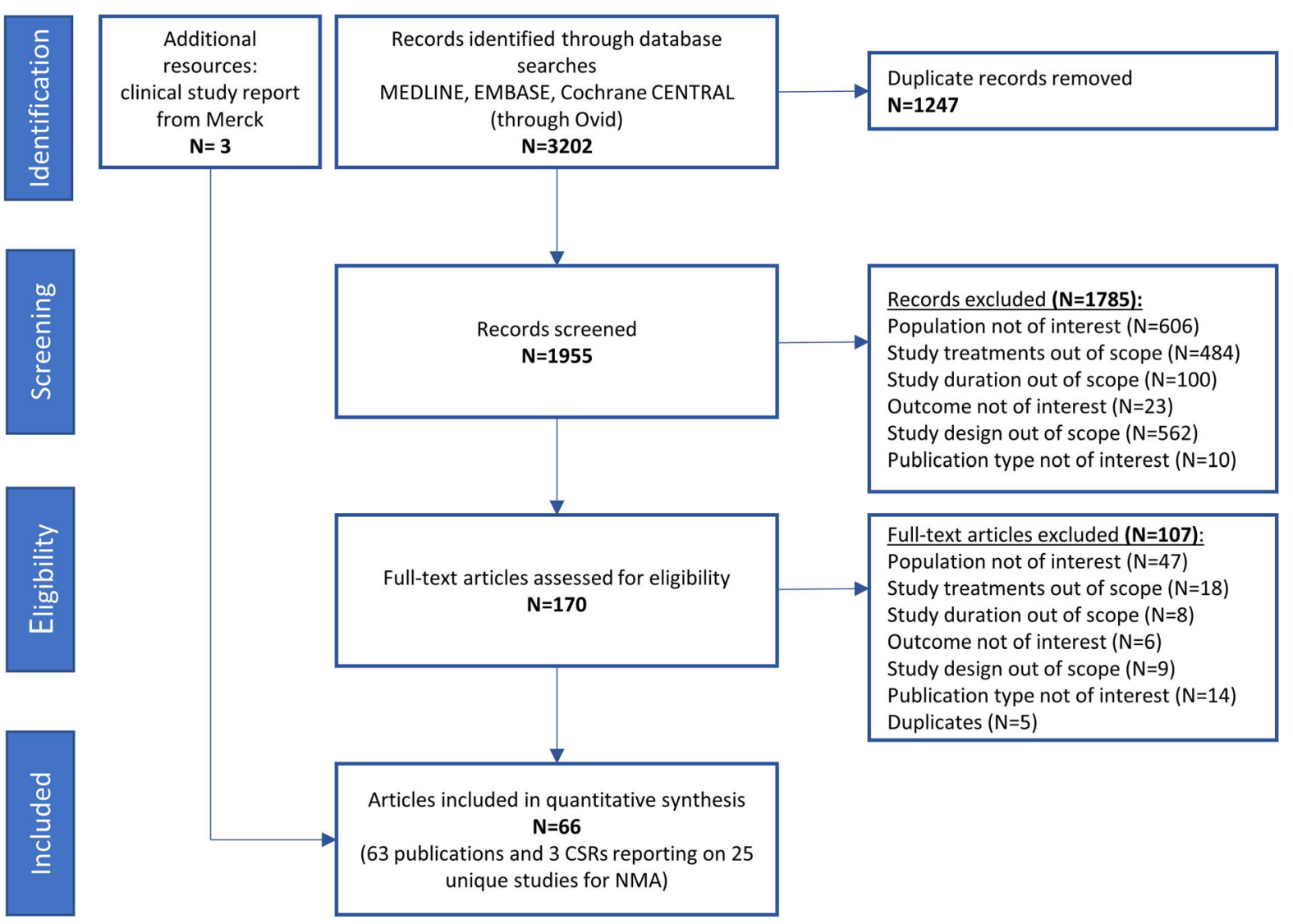

Fig. 1 PRISMA flowchart

outcomes and posterior median odds ratio for binary outcomes. Credible intervals (Crls) of 95\% were used to determine statistical significance. Crls were statistically significant for mean change if they did not include 0 or 1 for odds ratios. Uncertainties associated with treatment effect sizes are presented using the upper and lower limits of 95\% CIs. Ranking probabilities of treatments were derived using Surface Under the Cumulative Ranking Curve (SUCRA) and median rank for each treatment.

To understand how effect modifiers might impact the results of evidence synthesis, imbalances of effect modifiers across studies (i.e., heterogeneity) or across comparisons (i.e., inconsistency) were tested. Tests of inconsistency were performed based on methods presented in NICE DSU TSD 4 [17] to evaluate the agreement of indirect evidence and direct evidence. To assess the impact of study heterogeneity on the results, sensitivity analyses were performed for all outcomes by excluding studies with heterogeneity in effect modifiers.

\section{RESULTS}

\section{Systematic Literature Review}

The literature review identified 1955 non-duplicate publications. Upon completion of title and abstract review, 170 publications were retained for full-text review. After full-text review, 25 unique RCTs were included in the SLR, from 63 publications and 3 clinical study reports. Figure 1 displays the Preferred Reporting Items for Systematic Reviews and MetaAnalyses (PRISMA) diagram of studies included in the SLR. 


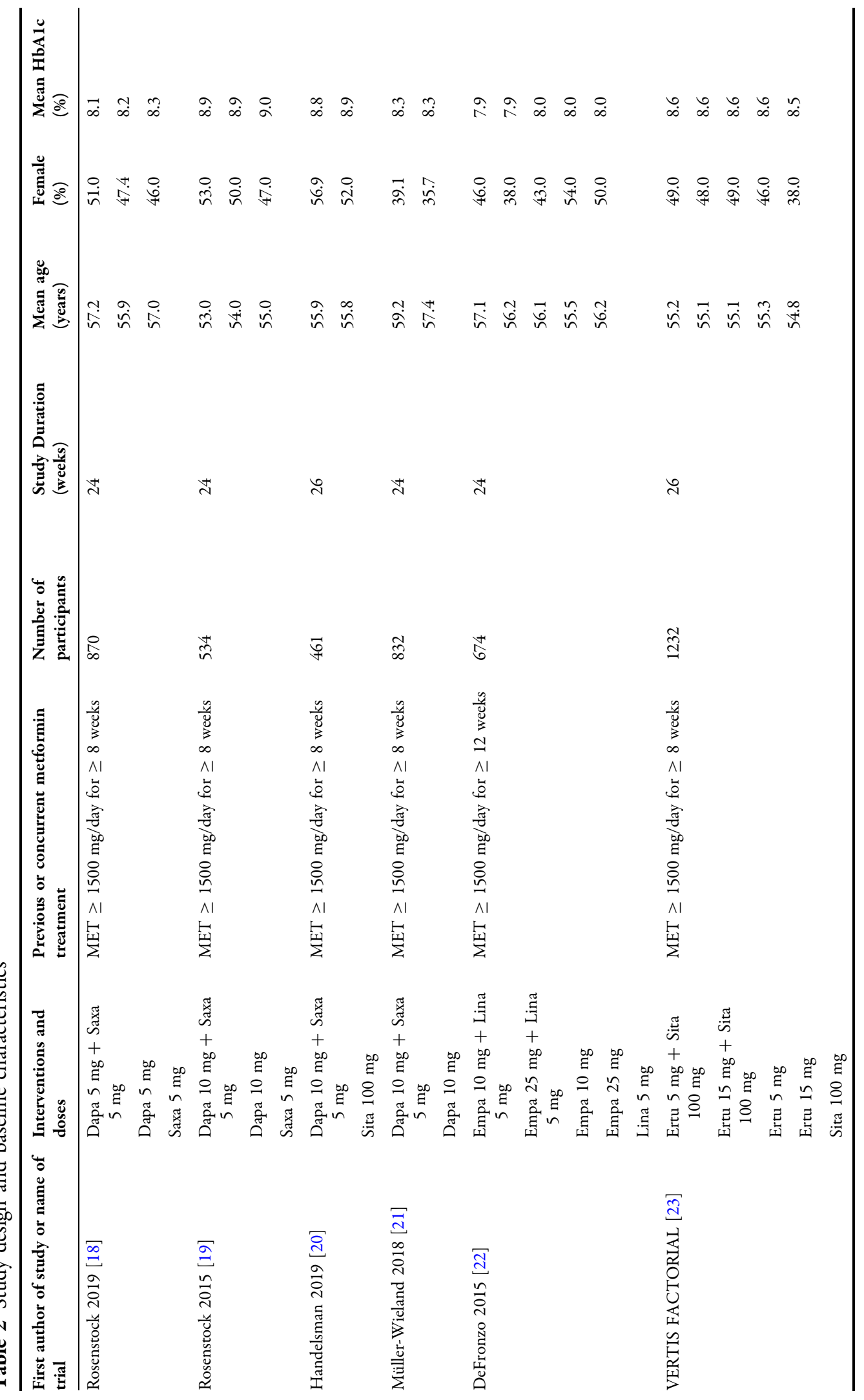




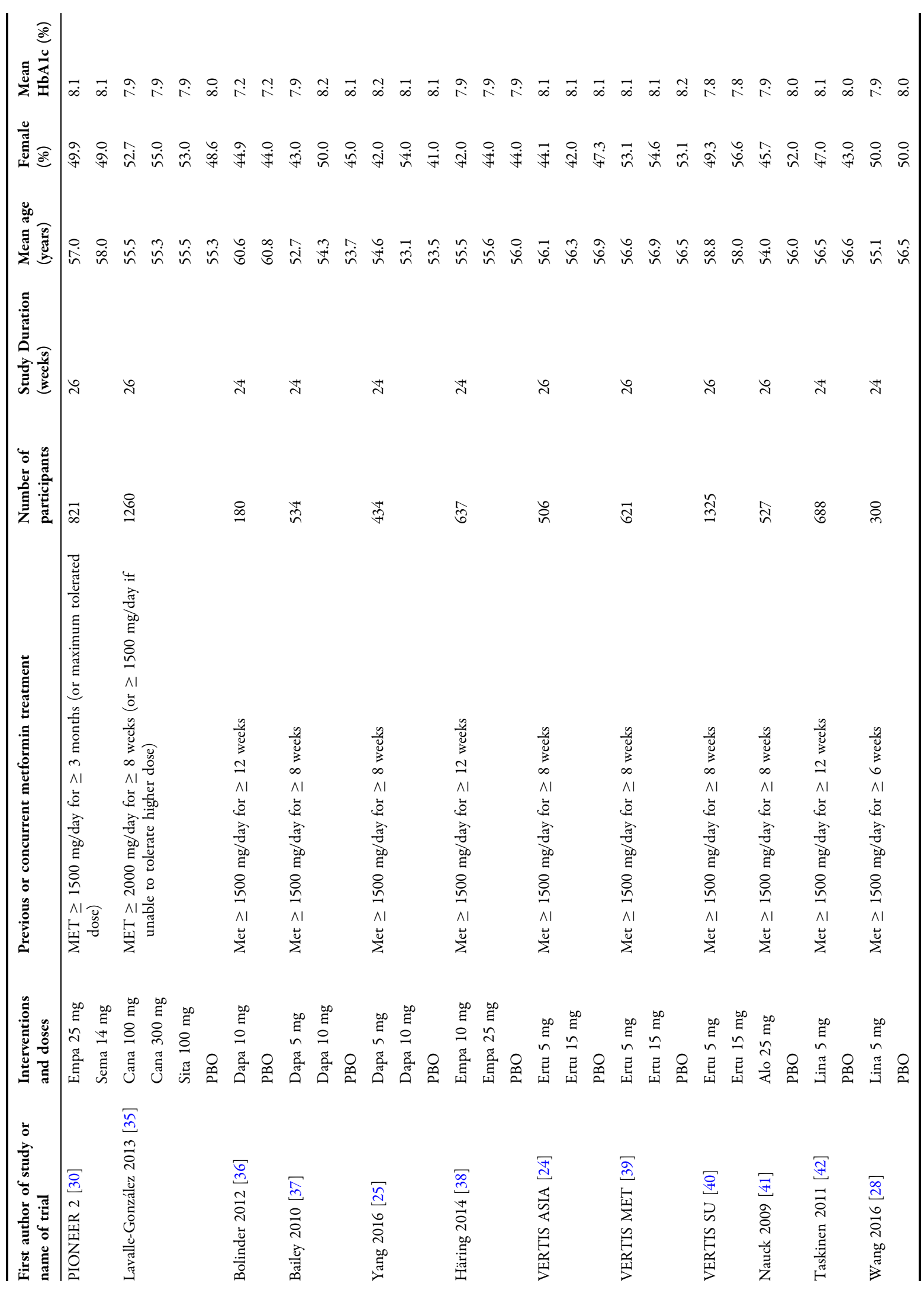




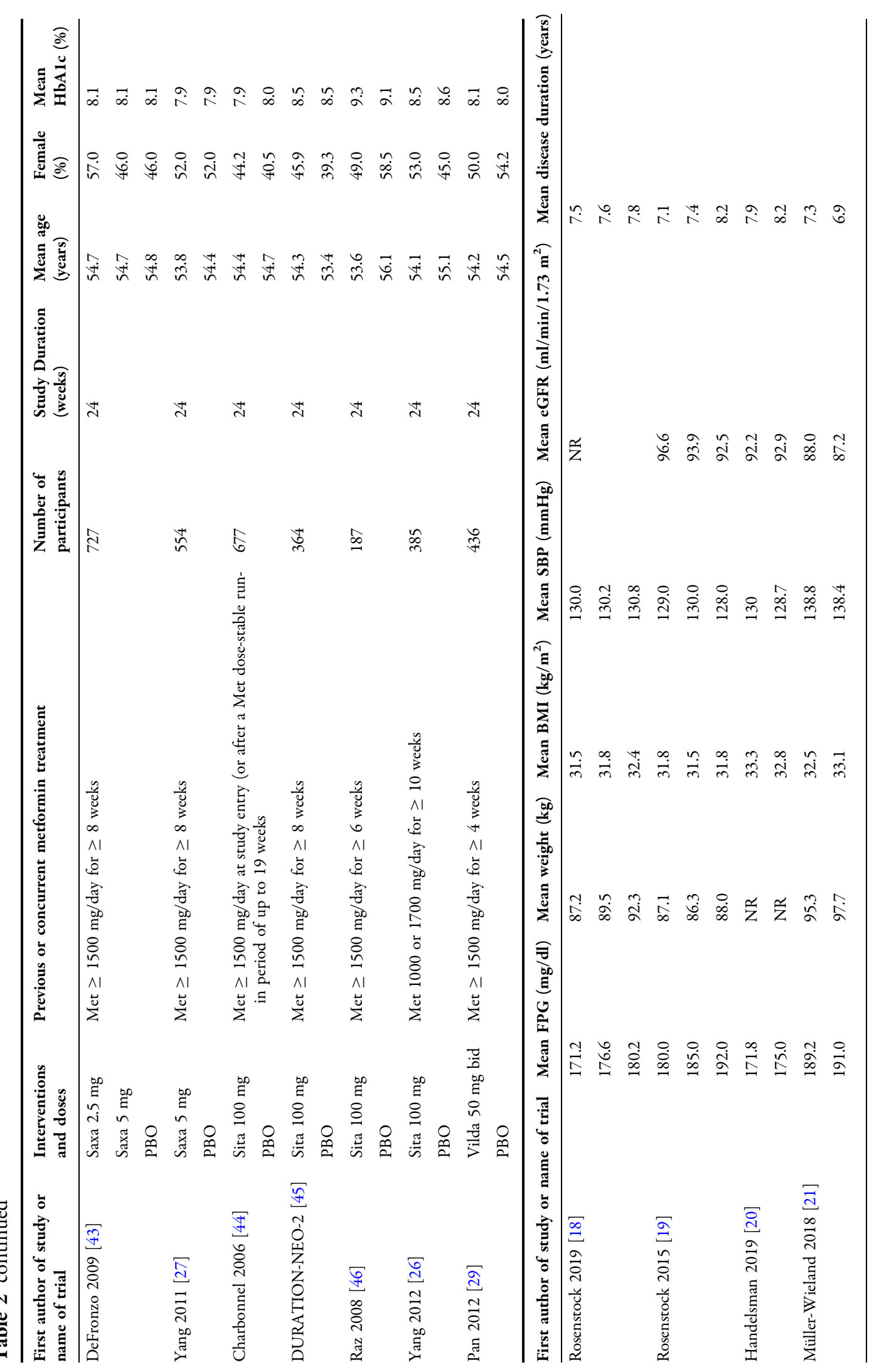




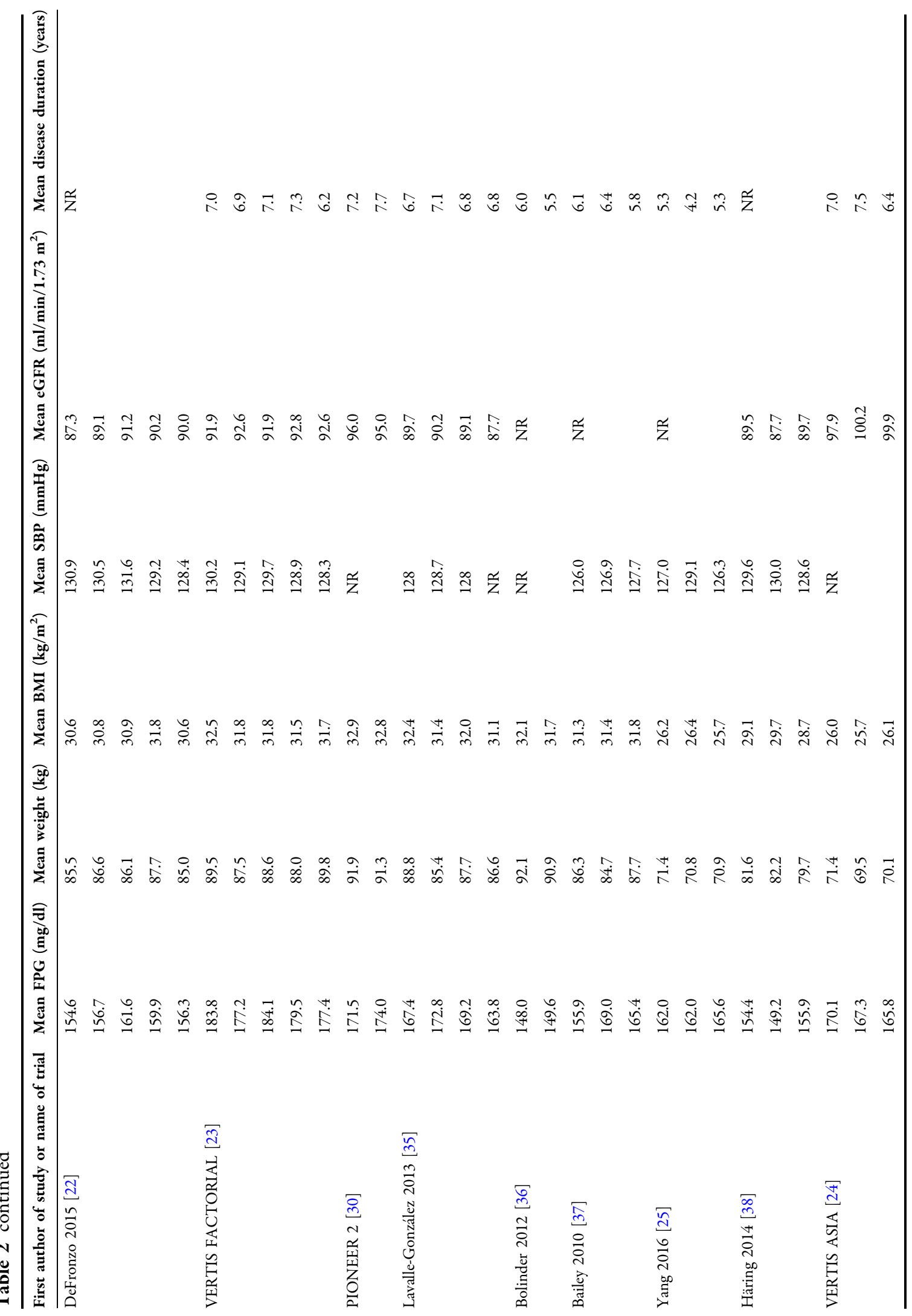




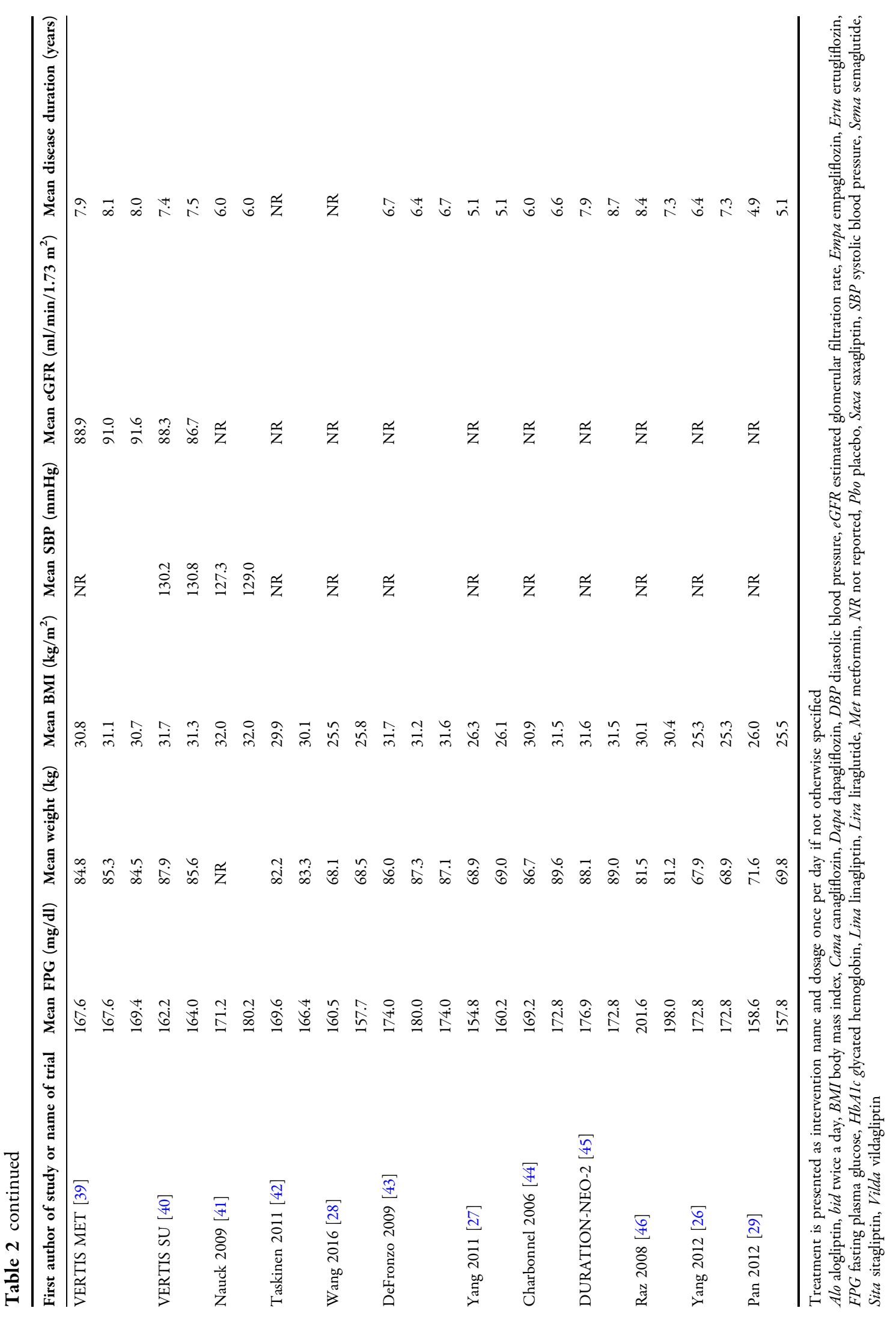


Study Characteristics, Outcomes, and Quality Assessment

Baseline characteristics for the study population of the 25 included studies are described in Table 2. Efficacy outcome data for all studies are available in the Supplementary Appendix Table 3. A total of 14 studies included SGLT-2 inhibitors with or without DPP-4 inhibitors, and 10 studies included DPP-4 inhibitors only, while 1 study included a GLP-1 receptor agonist single initiation therapy (PIONEER 2). A total of six studies reported the dual initiation of SGLT2 and DPP-4 inhibitors, of which four studies assessed the combination of dapagliflozin + saxagliptin [18-21] and one study each on the combination of empagliflozin + linagliptin [22] and ertugliflozin + sitagliptin [23]. The treatment groups were comparable within and across the included studies in terms of the mean baseline age (range 52.7-60.8 years) and mean baseline SBP (range 126-138.8 mmHg). Some differences were found in terms of mean baseline HbA1c (range 7.2-9.3\%), which could potentially influence the outcome on attaining HbA1c $<7 \%$. However, it was decided that the levels of baseline HbA1c were acceptable for comparison and differences were not egregious enough to exclude studies based on this factor, and we opted in favor of maintaining a comprehensive evidence base. The mean baseline weight ranged from 67.9 to $97.7 \mathrm{~kg}$, with six Asian studies [24-29] reporting relatively lower mean baseline weight of $\leq 71.6 \mathrm{~kg}$ across treatment groups. Likewise, the mean baseline body mass index (BMI) was relatively lower in the six Asian studies (mean BMI $\leq 26.4$ ) compared to the other included studies (mean BMI range 28.7-33.3). Other potential effect modifiers, such as background therapy regimen, proportion of females, and duration of diabetes, were found to be relatively similar across all studies. The quality of individual studies was evaluated using the Revised Cochrane Risk of Bias Tool for Randomized Trials (RoB2) [14]. A low overall risk of bias was observed for $84 \%$ of the included studies, some concerns were observed for three studies, while one study (PIONEER 2) presented high risk of bias owing to its open-label comparison of empagliflozin $25 \mathrm{mg}$ versus semaglutide $14 \mathrm{mg}$ [30] (Supplementary Appendix Fig. 1).

\section{Network Meta-Analysis}

The NMA was found to be feasible for all outcomes-mean change from baseline to $24( \pm 2)$ weeks in HbA1c ( $\mathrm{N}=25$ studies), weight ( $\mathrm{N}=22$ studies), SBP $(\mathrm{N}=14$ studies), and DBP ( $\mathrm{N}=14$ studies)-and for the proportion of patients with $\mathrm{HbA} 1 \mathrm{c}<7 \%(\mathrm{~N}=21$ studies). The patients and study design characteristic were considered similar across the included studies, except that low weight and BMI were observed for six Asian studies, and potential high risk of bias was observed with the PIONEER 2 openlabel study [30]. Sensitivity analyses were conducted to remove these studies to assess the impact of these potential effect modifiers. The network diagrams and forest plots for key efficacy outcomes of change from baseline in mean HbA1c, weight, and SBP are shown in Figs. 2 and 3 , respectively. The corresponding tables on the pairwise comparisons are presented in Table 3 through Table 5. SUCRA values and median rank are presented in Supplementary Appendix Table 4. The network diagrams, forest plots, and pairwise comparison league tables for the other efficacy outcomes assessed in the NMA are provided in the supplementary appendix.

The test of inconsistency performed for the overall network of evidence as per the NICE DSU TSD 4 [17] recommendations indicated a certain degree of inconsistency in the evidence base for the outcomes of interest, and the results are provided in supplementary appendix Table 5.

\section{Mean Change in HbA1c From Baseline}

The RE model was selected for all analyses of mean change in \% HbA1c from baseline, as a lower DIC value was observed with the RE model compared to the FE model. A lower DIC value indicates that the RE model was advisable for this outcome with an improved model fit and enhanced rigor (DIC difference: 9.0). All the dual and single initiation therapies 

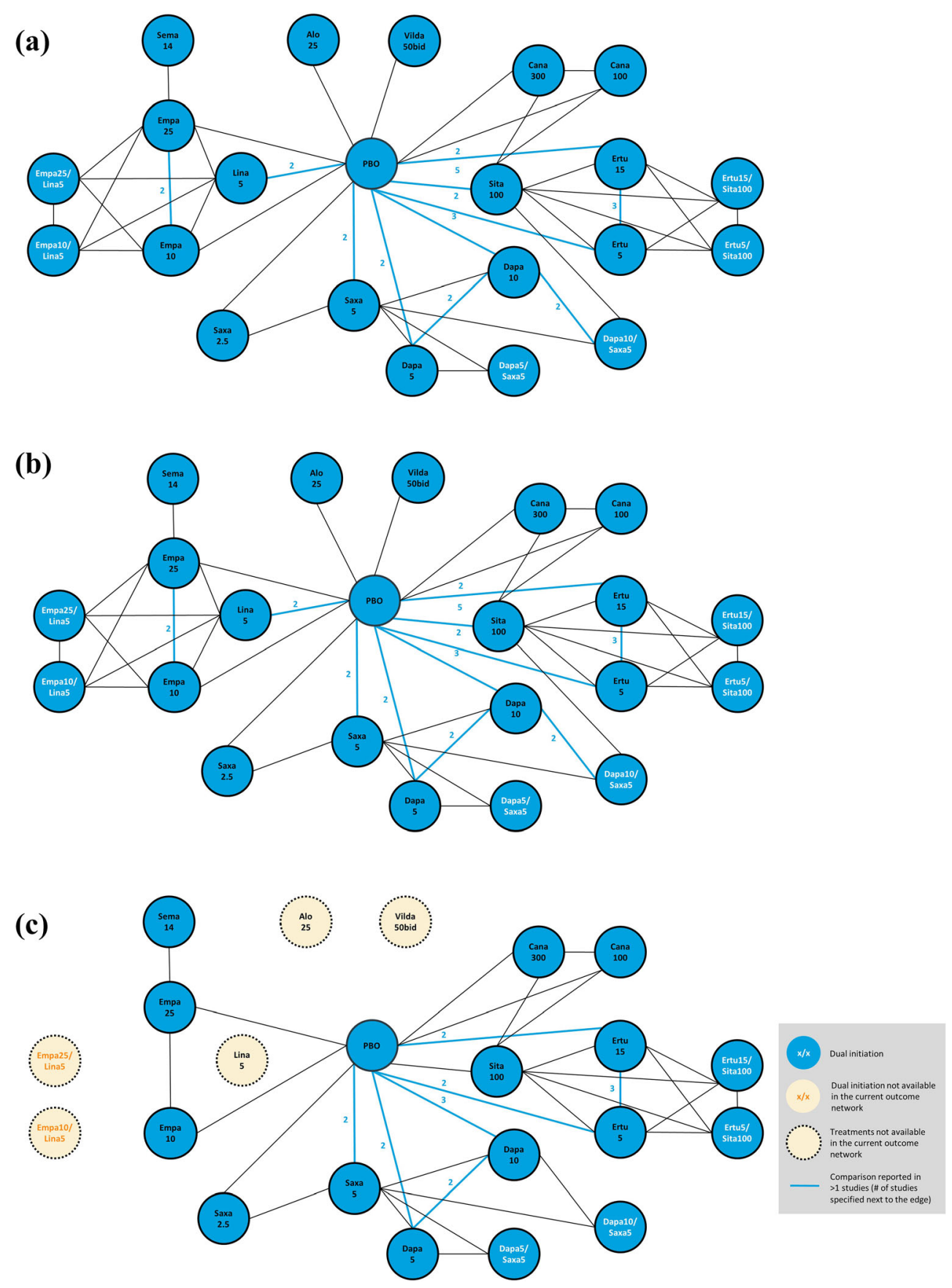

Fig. 2 Network diagrams of studies evaluating efficacy of antihyperglycemic agents in change from baseline in a HbAlc; b weight; c systolic blood pressure. Treatment dosages are presented as $\mathrm{mg}$ per day if not otherwise specified. All patients received metformin as background therapy. Only oral dosages approved in the US and EU were included in the network meta-analysis. Vilda is only approved in the EU, at $50 \mathrm{mg}$ twice a day (bid). Vilda is not approved in the US. Alo alogliptin, bid twice a day, Cana canagliflozin, Dapa dapagliflozin, Empa empagliflozin, Ertu ertugliflozin, EU, Europe, Exen exenatide, Glim glimepiride, Lina linagliptin, Lira liraglutide, PBO placebo, Saxa saxagliptin, Sema semaglutide, Sita sitagliptin, US United States, Vilda vildagliptin 
(a) Comparison Ertu $15 / S i t a 100$ vs. PBO
Ertu5/Sita 100 vs. PBO Empa25/Lina5 vs. PBO Empa10/Lina5 vs. PBO Sema14 vs. PBO Dapa10/Saxa5 vs. PBO Dapa5/Saxa5 vs. PBO

Cana300 vs. PBO

Ertu 15 vs. PBO

Ertu5 vs. PBO

Sita 100 vs. PBO

Cana 100 vs. PBO

Lina5 vs. PBO

Empa25 vs. $\mathrm{PBO}$

Dapa 10 vs. PBO

Saxa2.5 vs. PBO

Empa10 vs. PBO

Saxa5 vs. PBO

Vilda50bid vs. PBO

Alo25 vs. PBO

Dapa5 vs. PBO

(b)

$\begin{array}{ll}\text { Comparison } & \text { Dt (median) } 95 \% \mathrm{Cr} \\ \text { Ertu15 vs. PBO } & -2.92(-4.03,-1.89) \\ \text { Cana300 vs. PBO } & -2.54(-3.42,-1.70) \\ \text { Ertu15/Sita100 vs. PBO } & -2.37(-3.52,-1.27) \\ \text { Ertu5 vs. PBO } & -2.36(-3.44,-1.30) \\ \text { Cana100 vs. PBO } & -2.25(-3.12,-1.41) \\ \text { Sema14 vs. PBO } & -2.16(-3.37,-0.97) \\ \text { Empa25 vs. PBO } & -2.06(-2.81,-1.32) \\ \text { Dapa10 vs. PBO } & -2.00(-2.51,-1.49) \\ \text { Empa25/Lina5 vs. PBO } & -1.96(-3.04,-0.88) \\ \text { Ertu5/Sita100 vs. PBO } & -1.94(-3.10,-0.84) \\ \text { Dapa10/Saxa5 vs. PBO } & -1.66(-2.41,-0.94) \\ \text { Dapa5 vs. PBO } & -1.60(-2.27,-0.97) \\ \text { Empa10 vs. PBO } & -1.59(-2.33,-0.83) \\ \text { Empa10/Lina5 vs. PBO } & -1.56(-2.63,-0.48) \\ \text { Dapa5/Saxa5 vs. PBO } & -1.50(-2.58,-0.39) \\ \text { Saxa2.5 vs. PBO } & -0.49(-1.43,0.47) \\ \text { Alo25 vs. PBO } & -0.29(-1.28,0.72) \\ \text { Sita100 vs. PBO } & -0.10(-0.67,0.41) \\ \text { Saxa5 vs. PBO } & 0.10(-0.43,0.67) \\ \text { Vilda50bid vs. PBO } & 0.31(-0.65,1.24) \\ \text { Lina5 vs. PBO } & 0.35(-0.29,1.00)\end{array}$

t (median) $95 \% \mathrm{Cr}$

$-1.21(-1.48,-0.95)$

$-1.18(-1.45,-0.91)$

$-1.12(-1.40,-0.83)$

$-1.01(-1.29,-0.72)$

$-0.99(-1.33,-0.64)$

$-0.98(-1.19,-0.78)$

$-0.87(-1.15,-0.59)$

$-0.81(-1.05,-0.57)$

$-0.78(-0.95-0.62)$

$-0.72(-0.89-0.55)$

$-0.72(-0.85,-0.59)$

$-0.66(-0.90,-0.42)$

$-0.60(-0.77,-0.43)$

$-0.59(-0.80,-0.37)$

$-0.58(-0.73,-0.44)$

$-0.57(-0.84,-0.29)$

$-0.57(-0.78,-0.35)$

$-0.51(-0.67,-0.36)$

$-0.51(-0.83,-0.19)$

$-0.50(-0.87,-0.14$

$-0.49(-0.66,-0.32)$

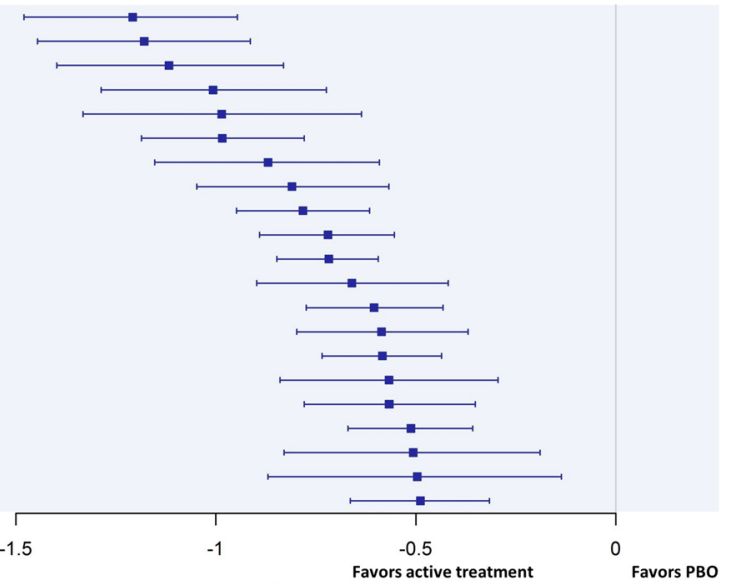

Favors active treatment

Favors PBO

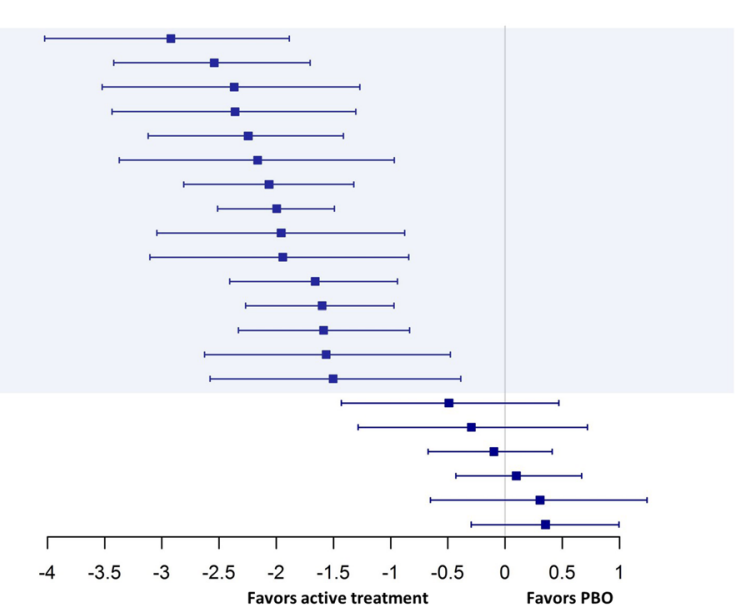

(c)

$\begin{array}{ll}\text { Comparison } & \text { Dt (median) } 95 \% \mathrm{Cr} \\ \text { Cana300 vs. PBO } & -6.63(-8.57,-4.66) \\ \text { Ertu15 vs. PBO } & -6.60(-9.28,-3.92) \\ \text { Ertu15/Sita100 vs. PBO } & -6.31(-9.09,-3.51) \\ \text { Ertu5 vs. PBO } & -6.27(-8.95,-3.57) \\ \text { Ertu5/Sita100 vs. PBO } & -6.06(-8.87,-3.23) \\ \text { Cana100 vs. PBO } & -5.34(-7.26,-3.41) \\ \text { Empa25 vs. PBO } & -4.80(-6.73,-2.86) \\ \text { Sema14 vs. PBO } & -4.80(-7.65,-1.94) \\ \text { Dapa10 vs. PBO } & -4.15(-5.87,-2.45) \\ \text { Empa10 vs. PBO } & -4.10(-6.03,-2.17) \\ \text { Dapa5/Saxa5 vs. PBO } & -3.53(-5.72,-1.36) \\ \text { Dapa5 vs. PBO } & -3.48(-5.27,-1.69) \\ \text { Sita100 vs. PBO } & -3.31(-5.26,-1.34) \\ \text { Dapa10/Saxa5 vs. PBO } & -3.24(-5.90,-0.60) \\ \text { Saxa5 vs. PBO } & -1.48(-3.17,0.23) \\ \text { Saxa2.5 vs. PBO } & -1.09(-4.16,2.00)\end{array}$

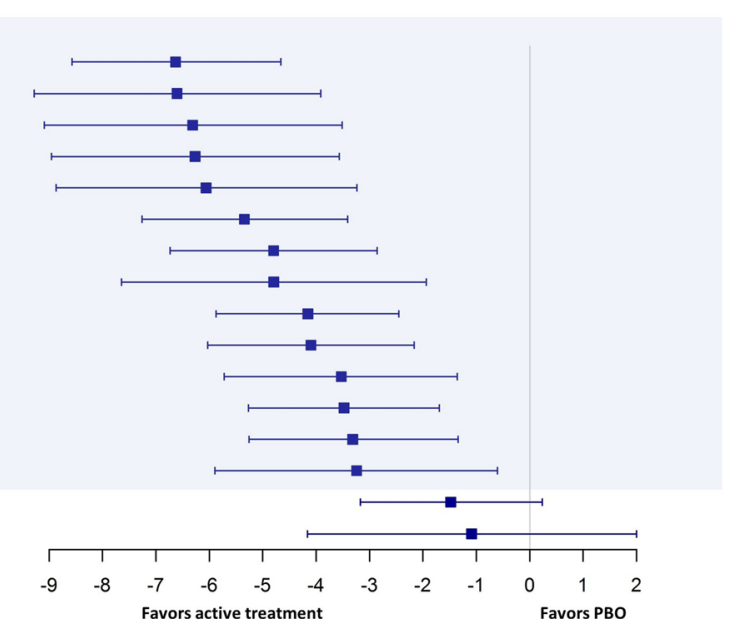


4Fig. 3 Forest plots for mean difference in efficacy outcomes in active treatment versus placebo groups: a HbAlc mean change from baseline (\%; RE); b weight mean change from baseline (kg; RE); c SBP mean change from baseline ( $\mathrm{mmHg}$; FE). For difference in mean change from baseline, lower values $(<0)$ indicate more favorable results. Credible intervals not including 0 indicate statistically significant difference, which are highlighted in blue in the figure. Alo alogliptin, bid twice a day, Cana canagliflozin, CrI Credible interval, Dapa dapagliflozin, $D t$ mean difference between treatments, Empa empagliflozin, Ertu ertugliflozin, FE fixed effects model, $H b A 1 c$ glycated hemoglobin, Lina linagliptin, Lira liraglutide, $P b o$ placebo, $R E$ random effects model, Saxa saxagliptin, SBP systolic blood pressure, Sema semaglutide, Sita sitagliptin, Vilda vildagliptin

demonstrated statistically significant reductions (i.e., improvement) in HbA1c from baseline compared to placebo (Fig. 3a).

In addition, the pairwise comparison between active treatments indicated more favorable results with dual initiation therapies than single initiation therapies (Table 3). In particular, the change in HbA1c from baseline was statistically significantly greater with ertugliflozin $5 \mathrm{mg}+$ sitagliptin $100 \mathrm{mg}$ and ertugliflozin $15 \mathrm{mg}+$ sitagliptin $100 \mathrm{mg}$ dual initiation therapies than with all single initiation therapies except semaglutide $14 \mathrm{mg}$. Semaglutide $14 \mathrm{mg}$ had no statistically significant difference compared with all dual initiation therapies.

\section{Mean Change in Weight From Baseline}

For mean change in weight from baseline, the RE model was selected for all analyses since the DIC value was lower for the RE model compared to the FE model by 3.7 points, suggesting that the RE model was advisable. A significantly greater reduction in mean weight was observed compared to placebo for all dual initiation therapies, single initiated SGLT-2 inhibitors, and semaglutide. However, none of the DPP-4 inhibitors (saxagliptin $2.5 \mathrm{mg}$, alogliptin $25 \mathrm{mg}$, sitagliptin $100 \mathrm{mg}$, saxagliptin $5 \mathrm{mg}$, vildagliptin $50 \mathrm{mg}$ twice a day [bid], and linagliptin $5 \mathrm{mg}$ ) showed statistically significant differences in weight reduction compared to placebo (Fig. 3b).

In the pairwise comparison of active treatments (Table 4), all dual initiation therapies were associated with a statistically significant reduction in weight compared to DPP-4 single initiation therapies of sitagliptin $100 \mathrm{mg}$, saxagliptin $5 \mathrm{mg}$, vildagliptin $50 \mathrm{mg}$ bid, and linagliptin $5 \mathrm{mg}$. Pairwise comparisons of the dual initiation therapies to the remaining single initiation therapies were not statistically significant. Weight reduction was similar across all dual initiation therapies.

\section{Mean Change in Systolic Blood Pressure From Baseline}

For mean change in SBP, the DIC of the FE model was lower than the RE model by 0.8 point. In addition, since the SBP outcomes were reported in only 14 studies and there were minimal variations across included studies in terms of baseline mean SBP, the FE model was preferred and selected for all the analyses of mean change in SBP. Compared to placebo, all the dual initiation therapies and 10 of the 12 single initiation therapies demonstrated statistically significant improvements in SBP. However, saxagliptin $5 \mathrm{mg}$ and saxagliptin $2.5 \mathrm{mg}$ showed only a trend of more favorable results compared to placebo (Fig. 3c).

For the pairwise comparison of active treatments in decreasing SBP, both the ertugliflozin dual initiation therapies (i.e., ertugliflozin $5 \mathrm{mg}+$ sitagliptin $100 \mathrm{mg}$ and ertugliflozin $15 \mathrm{mg}+$ sitagliptin $100 \mathrm{mg}$ ) were associated with a significantly greater reduction of SBP compared to single initiation therapies of all DPP-4 inhibitors in the analysis (saxagliptin $2.5 \mathrm{mg}$, saxagliptin $5 \mathrm{mg}$, and sitagliptin $100 \mathrm{mg}$; Table 5). For the other dual initiation therapies, dapagliflozin $5 \mathrm{mg}+$ saxagliptin $5 \mathrm{mg}$ showed significantly greater reductions of SBP compared with saxagliptin $5 \mathrm{mg}$ $(-2.05 \mathrm{mmHg}$ [95\% CrI $-3.74,-0.37])$. However, a statistically significantly greater reduction of SBP was observed for canagliflozin $300 \mathrm{mg}$ compared with dapagliflozin $5 \mathrm{mg}+$ saxagliptin $5 \mathrm{mg}(-3.10 \mathrm{mmHg}$ [95\% 


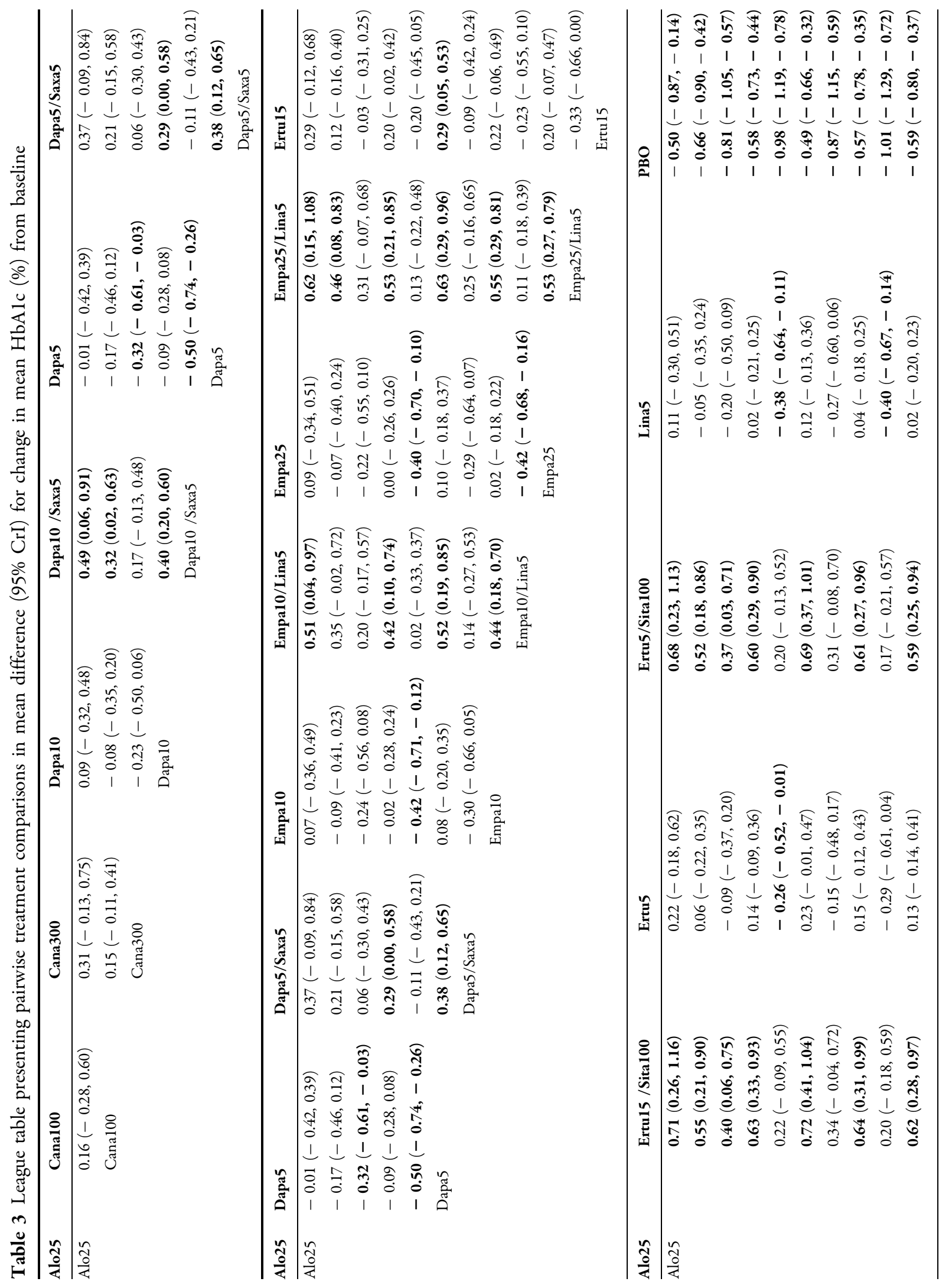




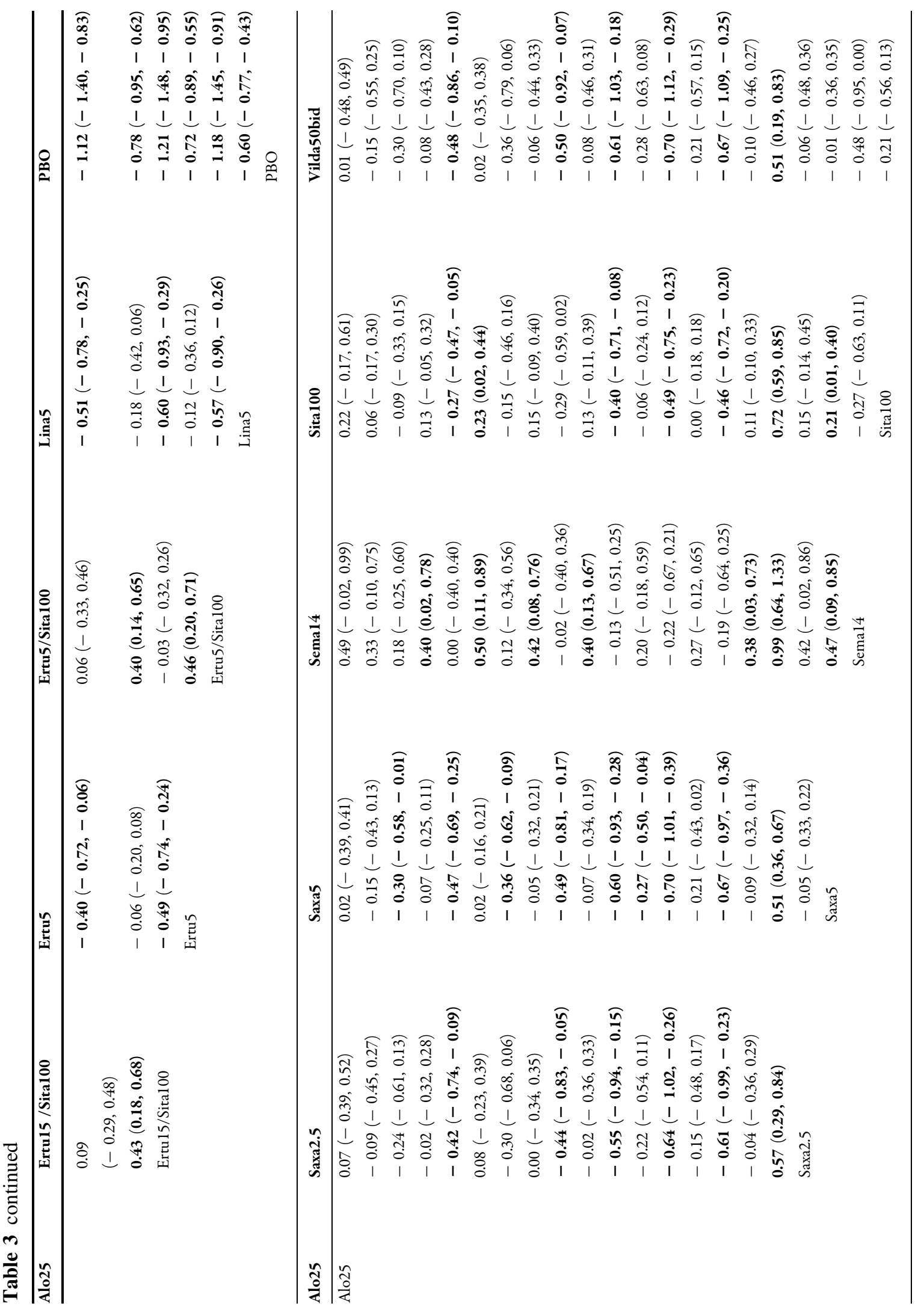




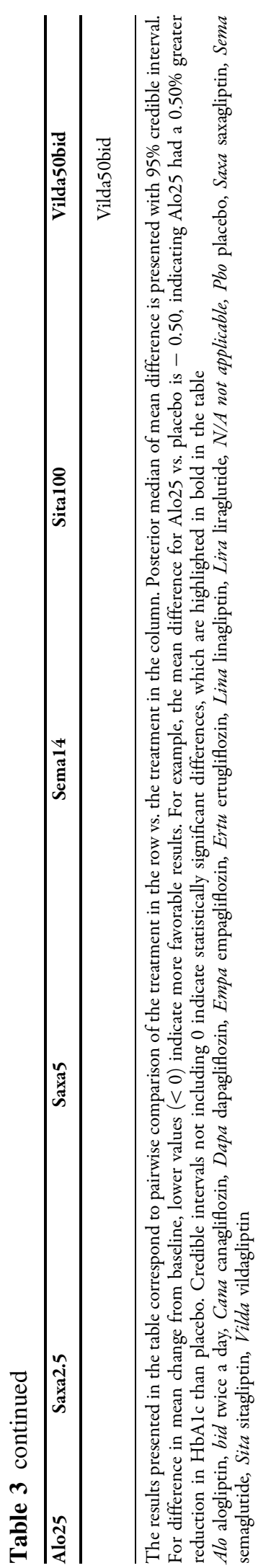

CrI - 5.98, - 0.16]) and dapagliflozin $10 \mathrm{mg}+$ saxagliptin $5 \mathrm{mg}(-3.37 \mathrm{mmHg}[95 \%$ CrI - 6.65, - 0.09]).

\section{Other Outcomes}

For mean change in DBP from baseline, the FE model was selected for all analyses since the DIC value was lower for the FE model compared to the RE model by 1.85 points. Compared to placebo, ertugliflozin $15 \mathrm{mg}+$ sitagliptin $100 \mathrm{mg}$, dapagliflozin $5 \mathrm{mg}+$ saxagliptin $5 \mathrm{mg}$, and 9 of the 12 single initiation therapies demonstrated statistically significant improvements in DBP (Supplementary Appendix Fig. 3a). For the number of patients meeting the HbA1c target (HbA1c $<7 \%)$, the RE model was selected for all analyses since the DIC value was lower for the RE model compared to the FE model (DIC difference: 3.5). The odds of achieving the HbA1c target $(<7 \%)$ were statistically significantly higher for all dual initiation therapies and 14 out of 15 single initiation therapies (except dapagliflozin $5 \mathrm{mg}$ ) compared to placebo (Supplementary Appendix Fig. 3b). The pairwise comparison league tables for the change in DBP from baseline and proportion of patients achieving HbA1c $>7 \%$ are provided in supplementary Appendix Tables 6 and 7, respectively.

\section{Sensitivity Analysis Results}

In the sensitivity analyses removing the PIONEER 2 open-label study, results were consistent with the base case analysis, and no substantial impact was observed for the comparative efficacy among active treatments versus placebo (Supplementary Appendix Fig. 4). Removing the six Asian studies with low baseline weight and BMI also did not alter the direction of treatment effect or statistical significance for change in HbA1c, weight, and proportion of patients achieving the HbA1c target $(<7 \%)$. However, as opposed to the statistically favorable results observed in the base case analysis, the sensitivity analysis results indicated no statistically significant difference for SBP reduction with the two dapagliflozin + saxagliptin dual 


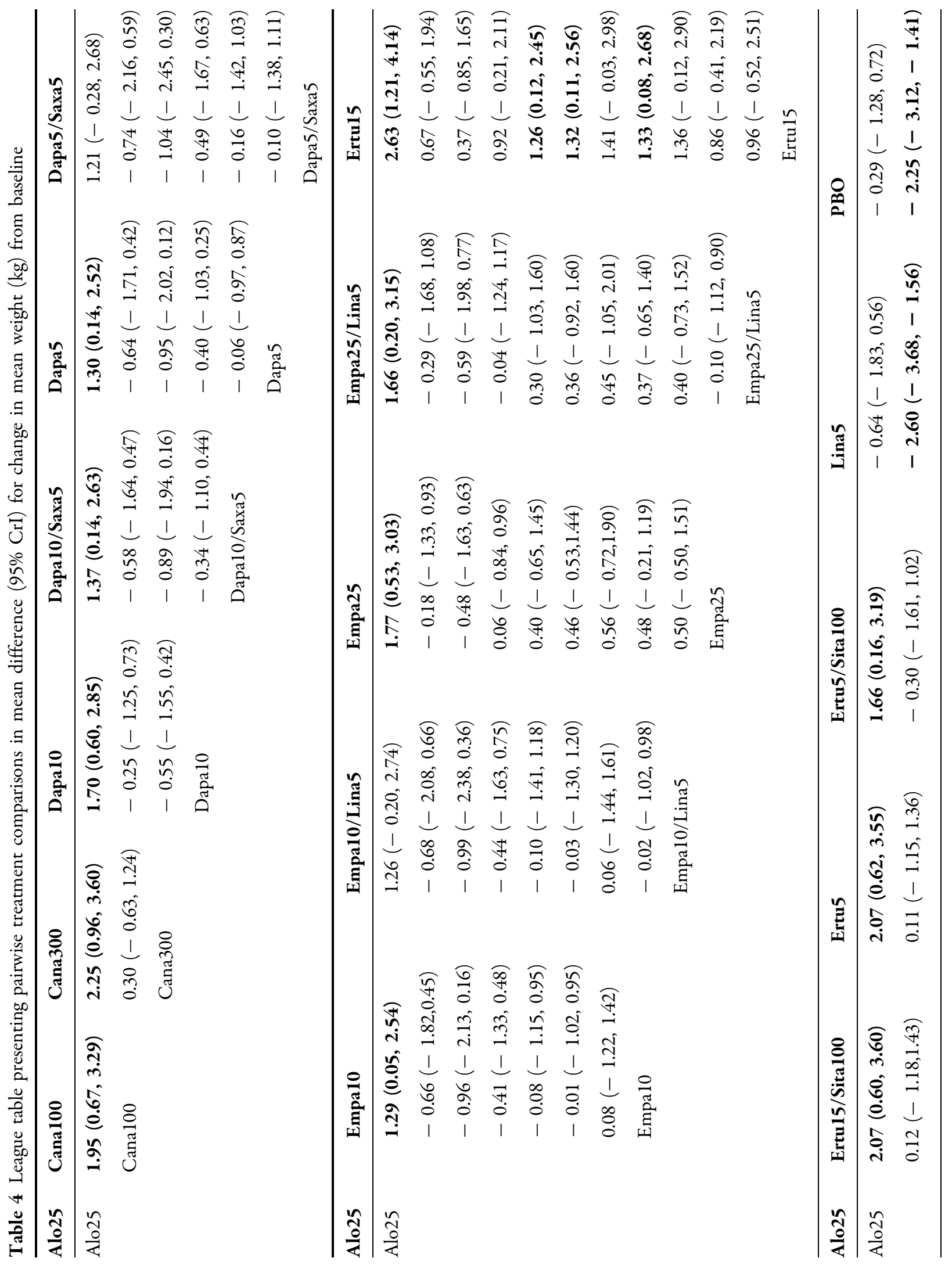




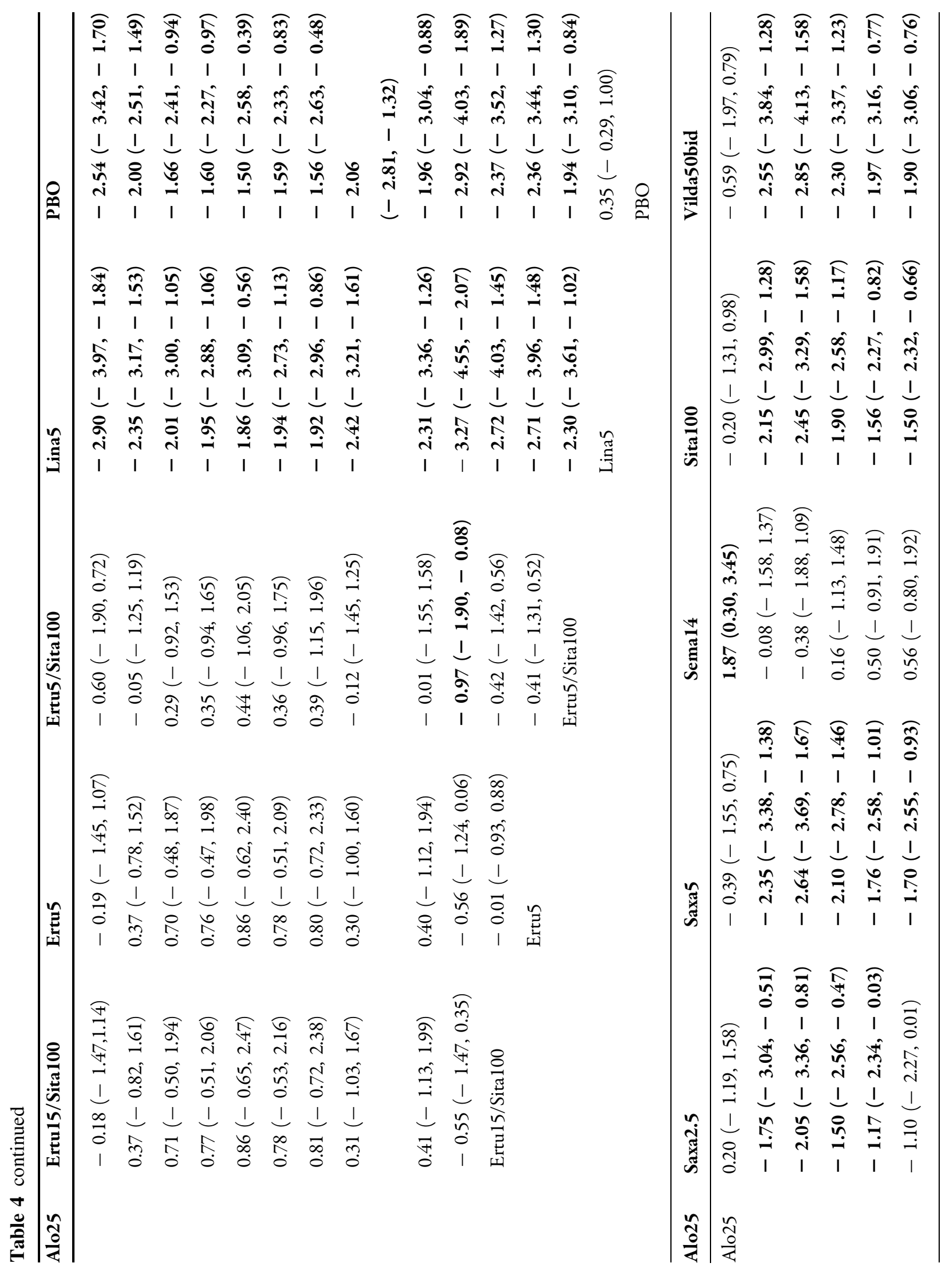




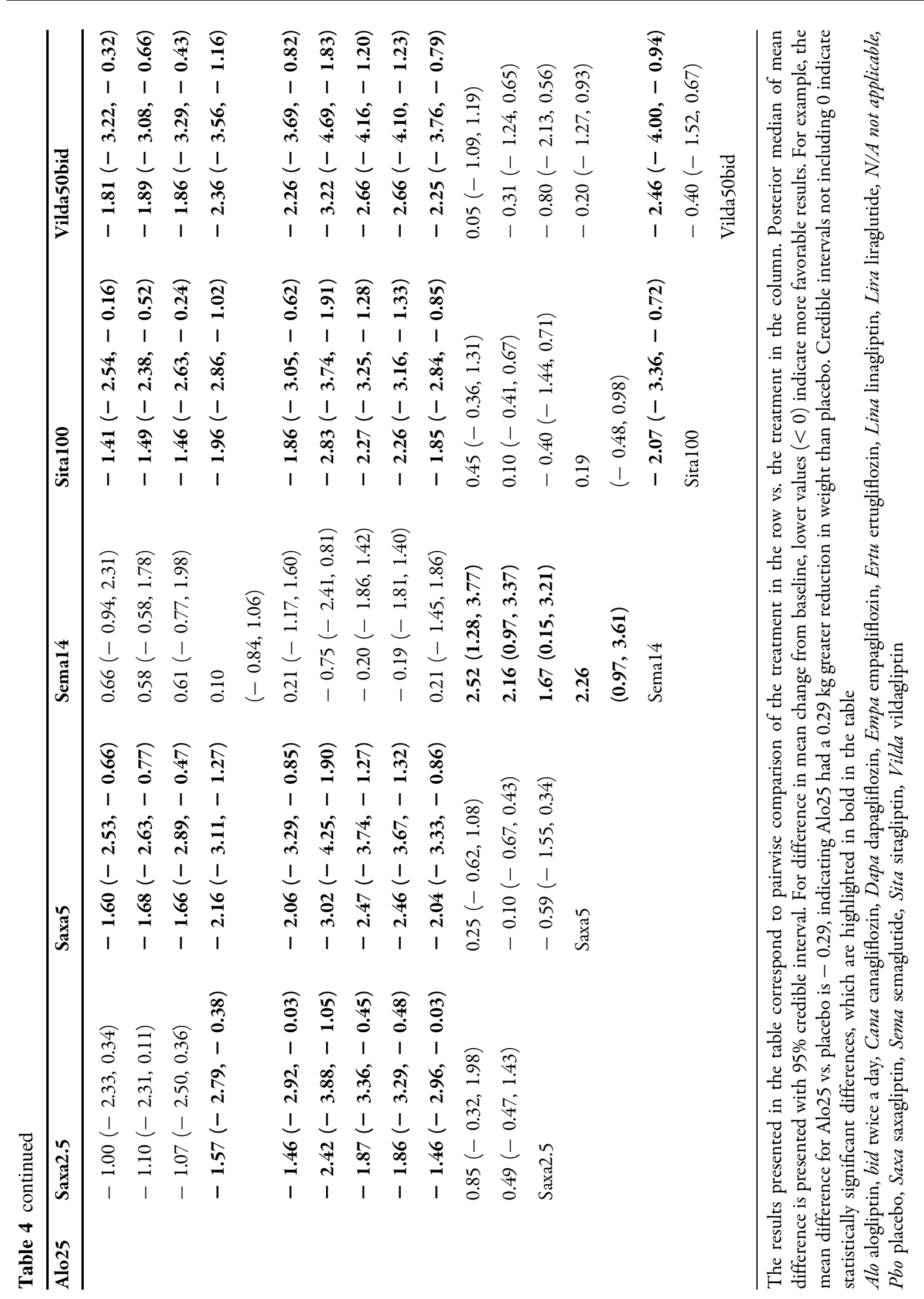




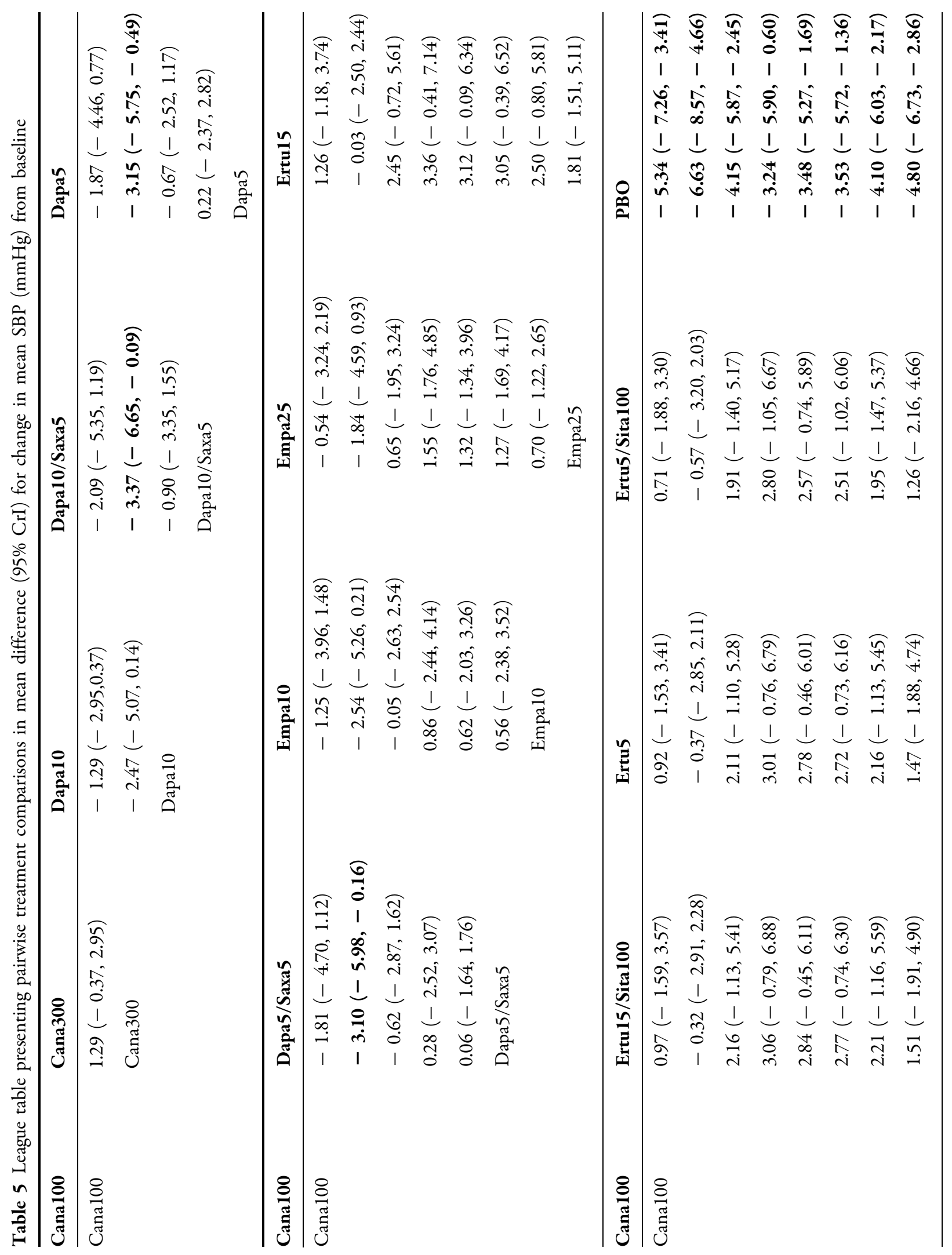




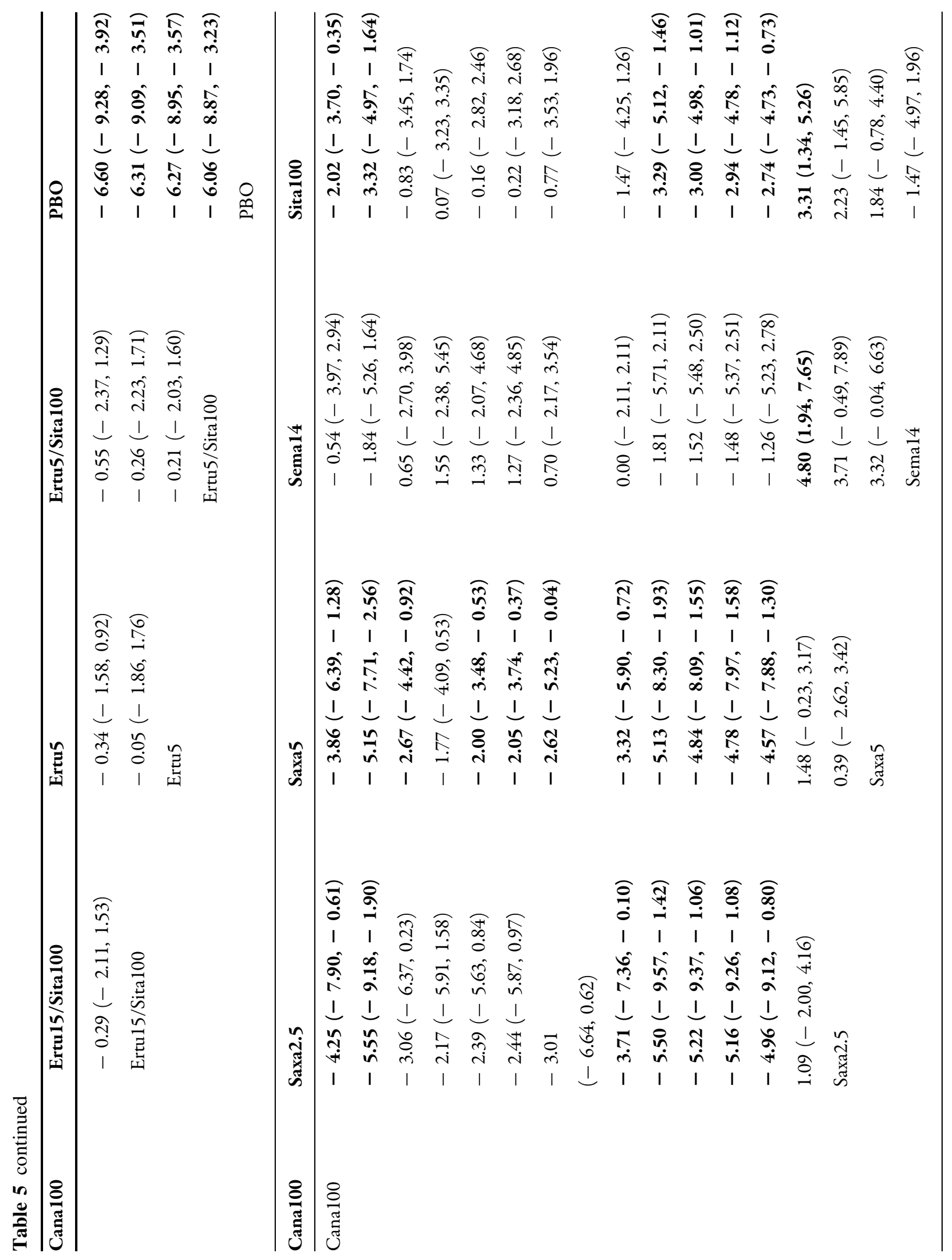




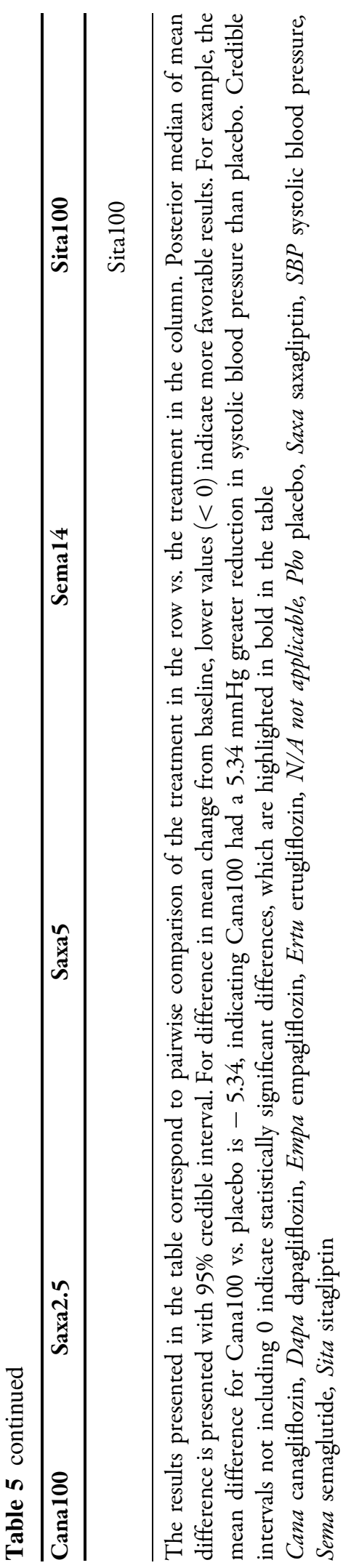

initiation therapies and with dapagliflozin $5 \mathrm{mg}$ compared to placebo as well as no statistically significant difference in DBP reduction with dapagliflozin $5 \mathrm{mg}$ or $10 \mathrm{mg}$ for DBP reduction comparison to placebo (Supplementary Appendix Fig. 5).

\section{DISCUSSION}

This NMA was conducted to provide a comprehensive understanding of oral antihyperglycemic agents as dual initiation therapy compared with single initiation to support clinical decision making and treatment guideline development. The evidence base was synthesized from high-quality data available from the latest RCTs on the efficacy of antihyperglycemic agents as add-on treatment to metformin in T2DM patients. This is one of the first NMAs conducted to understand the comparative efficacy of single and dual initiation therapies of currently approved oral agents (SGLT-2 inhibitors, DPP-4 inhibitors, and GLP-1 receptor agonists) in combination with metformin. Prior NMAs have mostly focused on single initiation therapies. McNeill et al. compared ertugliflozin with other antihyperglycemic agents as single add-on therapy in patients uncontrolled on metformin alone [8]. Another NMA by Mearns et al. studied adjunctive antidiabetic agents in patients with inadequately controlled T2DM on metformin alone, which included the dual initiation therapy of empagliflozin + linagliptin in the comparison with other single initiation therapies; however, the more recent dual initiation regimens involving dapagliflozin or ertugliflozin were not evaluated in this study [9].

Overall, as demonstrated in our NMA, most dual initiation therapies showed better glycemic control compared to single initiation therapy with SGLT-2 inhibitors and DPP-4 inhibitors as add-on treatment to metformin. Dual initiation therapy may induce early significant reduction of HbA1c levels and serve as an option to avoid stepwise treatment intensification for those who are uncontrolled on metformin monotherapy [31]. Among the single initiation therapies, GLP-1 receptor agonists (semaglutide $14 \mathrm{mg}$ ) showed the most favorable glycemic 
control and had a statistically significantly greater reduction in HbA1c than several single initiation therapies. However, dual initiation therapies including high- and low-dose ertugliflozin + sitagliptin and empagliflozin + linagliptin showed a trend of better glycemic control than the oral GLP-1 receptor agonist, although this was not statistically significant. In this NMA, dual initiation therapies lead to large reductions in HbA1c levels and thus may be suitable for patients requiring significant $\mathrm{HbA1c}$ reductions after failing metformin monotherapy.

This NMA also demonstrated that dual initiation therapies can be more effective than some single initiation therapies in weight reduction, in particular DPP-4 inhibitors. Given the link between T2DM and obesity [32], adding an antihyperglycemic that is at least weight neutral is necessitated, while antihyperglycemic agents that promote weight loss could also be desired. Among the single initiation therapies, SGLT-2 inhibitors and GLP-1 receptor agonists (semaglutide $14 \mathrm{mg}$ ) were found to be more effective, while none of the single initiation DPP-4 inhibitors were significantly effective in reducing body weight compared to placebo. These findings are in line with the ADA and EASD guidelines $[4,5]$.

Single initiation therapies with SGLT-2 inhibitors and dual initiation therapies were also associated with a similar decrease in SBP and relatively more favorable results compared to single add-on DPP-4 inhibitors. This finding could potentially be important for patients with T2DM who also have blood pressure concerns. The SBP-lowering effect of SGLT2 inhibitors observed in this NMA is consistent with a metaanalysis by Baker et al. who reported significant reductions in SBP from baseline with SGLT2 inhibitors compared to study-specific controls in RCTs, both in active-controlled RCTs (weighted mean difference [WMD] $-4.2 \mathrm{mmHg}$ [95\% CI $-4.9,-3.5])$ and in placebo-controlled RCTs (WMD - $3.8 \mathrm{mmHg}$ [95\% CI - 4.4, - 3.2]) [33]. Another NMA on adjunctive antidiabetic agents in patients with inadequately controlled T2DM on metformin alone also demonstrated statistically significant reductions in SBP with empagliflozin + linagliptin compared to linagliptin, saxagliptin, and sitagliptin, in addition to showing a significant decrease in SBP compared with placebo (WMD - $5.43 \mathrm{mmHg}$ [95\% CI - 8.39, - 2.47]) [9].

This NMA demonstrated that dual initiation therapies were similar or more favorable than single initiation therapies regarding efficacy. Although comparison among single initiation therapies was not a focus of this research, such results were also available as part of this NMA and could be used to inform the comparative efficacy of single initiation therapies in patients uncontrolled on metformin. McNeill et al. compared ertugliflozin with canagliflozin, empagliflozin, and dapagliflozin as single addon therapy in three different populations [8]. In the patients who were uncontrolled on metformin alone, they found that ertugliflozin $5 \mathrm{mg}$ was more effective in lowering HbA1c than dapagliflozin $5 \mathrm{mg}$, and ertugliflozin $15 \mathrm{mg}$ was more effective than dapagliflozin $10 \mathrm{mg}$ and empagliflozin $25 \mathrm{mg}$ [8]. When comparing the results from our NMA with the findings from the McNeill study, there were some minor numerical differences, but the overall trends were similar and credible intervals overlapped.

Among single initiation therapies evaluated in our NMA, the oral GLP-1 receptor agonist semaglutide at $14 \mathrm{mg}$ also demonstrated a relatively favorable efficacy profile, showing significantly greater reduction in $\mathrm{HbA1c}$ and weight compared to some of the single initiation SGLT2 and DPP-4 inhibitors. However, single initiation GLP-1 receptor agonist was comparable to dual initiation therapies. Note that only one study for the class of oral GLP-1 receptor agonists (PIONEER-2) was considered eligible for this NMA. Multiple trials in the PIONEER program were evaluated, but they did not meet the population criteria and were therefore not considered eligible for this analysis.

In addition to the proven efficacy of dual initiation over single initiation therapies, a previous study has also shown their merit in terms of cost-effectiveness. Pawaskar et al. conducted a long-term cost-effectiveness analysis evaluating the long-term cost-effectiveness of treatment intensification with combination DPP-4 inhibitors and SGLT-2 inhibitors 
compared to sulfonylureas and insulin in patients who fail to achieve glycemic control on metformin monotherapy [34]. This analysis demonstrated that combination therapy of DPP-4 inhibitors and SGLT-2 inhibitors in addition to metformin was cost-effective compared to a more generic treatment strategy with metformin and sulfonylureas prior to insulin initiation. Although the branded oral medication of DPP-4 inhibitors and SGLT-2 inhibitors had higher direct medical costs, the health benefits associated with this strategy partially offset the treatment costs, with improved life expectancy and quality of life. Considering its potentially favorable efficacy and cost-effectiveness profile, dual initiation therapies could be considered for T2DM patients not achieving adequate control with metformin.

\section{Limitations}

This study has some limitations. While interpreting our NMA results, it should be noted that inconsistencies were identified within loops of the network. This suggests that there were differences between the direct and indirect comparisons. Differences were observed between NMA and inconsistency models, with DIC differences ranging from 1.2 to 11.1 points. However, the detected inconsistency was at an acceptable level and therefore should not impact the overall interpretation. For baseline characteristics, the mean $\mathrm{HbA1c}$ ranged from 7.2 to $9.3 \%$ across the studies, which was considered borderline comparable. The varied HbA1c baseline could have an impact on the exploratory outcome for the proportion of patients attaining HbA1c $<7 \%$, since patients with higher baseline HbA1c are less likely to attain the fixed target. To address this limitation, in the analyses for HbA1c reduction and HbA1c within target outcomes, a RE model was used, which allowed for a distribution of the treatment effect and provided enhanced rigor in such cases with baseline variations. However, given that we identified an HbA1c mean change from baseline ranging from $-1.52 \%$ (reduction) to $0.15 \%$ (increase), whereas the baseline HbA1c levels range between 7.2 and $9.3 \%$, it should be acknowledged that reaching the HbA1c target $(<7 \%)$ could be more dependent on the baseline HbA1c levels than any effect of medication, and the results for this exploratory outcome should be interpreted with caution. Variations were also observed for mean weight at baseline, with lower weight/BMI observed in Asian studies. To address this, a RE model was also selected for the base case NMA, and additional sensitivity analyses were conducted to confirm the robustness of the results. For the impact of small studies, comparison-adjusted funnel plots were used to explore potential publication bias. Although the Egger and Thompson-Sharp methods did not identify publication bias for any outcome, the Begg-Mazumdar test detected asymmetry of the funnel plots, suggesting potential publication bias (results not shown). A comprehensive literature search was performed for this review, but we cannot rule out the possibility that some unpublished studies could be missing. Finally, previous studies and metaanalyses have highlighted the need to compare active dual or single initiation therapies in terms of safety over a long duration of followup. The scope of this current research did not include safety and long-term efficacy, and it is recommended that additional research should be conducted.

Despite these limitations, this NMA included a large evidence base with homogeneous studies and provided a thorough understanding of the comparative efficacy of dual and single initiation strategies in patients uncontrolled on metformin. Findings of our NMA could be used to inform future guidelines on the pharmacologic approach to attain glycemic control and adequate disease management for T2DM patients.

This NMA provides comprehensive insight for the key efficacy goals with the evidence available to date. However, there is still a lack of scientific evidence addressing treatment paradigms of sequential add-on versus dual initiation therapy. Carefully designed, prospective, high-quality real-world studies to assess the clinical effectiveness and tolerability of initial combinations compared with sequential treatment initiation in patients with new onset or poorly controlled T2DM are needed to fill this 
existing gap and have potential to provide further evidence to guide health-care policies and practices.

\section{CONCLUSION}

Add-on dual initiation therapies, particularly ertugliflozin + sitagliptin, demonstrated significantly better outcomes than most single initiation therapies in reducing $\mathrm{HbA1c}$, weight, and SBP over 24-26 weeks of follow-up in T2DM patients uncontrolled on metformin alone.

\section{ACKNOWLEDGEMENTS}

Funding. This study and associated editorial services were funded by Merck Sharp \& Dohme Corp., a subsidiary of Merck \& Co., Inc., Kenilworth, NJ, USA. The funder of the study was involved in the study design, result interpretation, and critical review of the results presented in this manuscript.

Editorial Assistance. Thank you to Sukanya Ghildiyal and Paranjoy Saharia from IQVIA Inc. who supported the development of the manuscript. IQVIA received funding from Merck Sharp \& Dohme Corp. for editorial assistance on the manuscript.

Authorship. All named authors meet the International Committee of Medical Journal Editors (ICMJE) criteria for authorship for this article, take responsibility for the integrity of the work as a whole, and have given their approval for this version to be published.

Disclosures. DL, AA, UA, and SR are employees of Merck Sharp \& Dohme Corp. EM is an employee of Pfizer Inc. YK, JH, RS, AN, and JU are employees of IQVIA Inc., which provides consulting and other research services to biopharmaceutical companies. IQVIA received funding from Merck Sharp \& Dohme Corp. to conduct this study and for editorial assistance on the manuscript.
Compliance with Ethics Guidelines. This article is based on previously conducted studies and does not contain any new studies with human participants or animals performed by any of the authors. A pre-specified protocol was developed prior to the conduct of the research. However, the systematic review was not registered in PROSPERO or other public registry platforms.

Data Availability. The datasets generated during and/or analyzed during the current study are available from the corresponding author on reasonable request.

Open Access. This article is licensed under a Creative Commons Attribution-NonCommercial 4.0 International License, which permits any non-commercial use, sharing, adaptation, distribution and reproduction in any medium or format, as long as you give appropriate credit to the original author(s) and the source, provide a link to the Creative Commons licence, and indicate if changes were made. The images or other third party material in this article are included in the article's Creative Commons licence, unless indicated otherwise in a credit line to the material. If material is not included in the article's Creative Commons licence and your intended use is not permitted by statutory regulation or exceeds the permitted use, you will need to obtain permission directly from the copyright holder. To view a copy of this licence, visit http://creativecommons.org/licenses/by$\mathrm{nc} / 4.0 /$.

\section{REFERENCES}

1. Bailey T. Options for combination therapy in type 2 diabetes: comparison of the ADA/EASD position statement and AACE/ACE algorithm. Am J Med. 2013;126(9 Suppl 1):S10-20.

2. Turner RC, Cull CA, Frighi V, Holman RR. Glycemic control with diet, sulfonylurea, metformin, or insulin in patients with type 2 diabetes mellitus: progressive requirement for multiple therapies (UKPDS 49). UK Prospective Diabetes Study (UKPDS) Group. JAMA. 1999;281(21):2005-12. 
3. ADA American Diabetes Association. Standards of medical care in diabetes-2020. Diabetes Care. 2020;43:S1-212.

4. Davies MJ, D'Alessio DA, Fradkin J, Kernan WN, Mathieu C, Mingrone $G$, et al. Management of hyperglycemia in type 2 diabetes, 2018. A Consensus Report by the American Diabetes Association (ADA) and the European Association for the Study of Diabetes (EASD). Diabetes Care. 2018;41(12): 2669-701.

5. Buse JB, Wexler DJ, Tsapas A, Rossing P, Mingrone G, Mathieu C, et al. 2019 Update to: management of hyperglycemia in type 2 diabetes, 2018. A Consensus Report by the American Diabetes Association (ADA) and the European Association for the Study of Diabetes (EASD). Diabetes Care. 2020;43(2): 487-93.

6. McEwen LN, Bilik D, Johnson SL, Halter JB, Karter AJ, Mangione CM, et al. Predictors and impact of intensification of antihyperglycemic therapy in type 2 diabetes: translating research into action for diabetes (TRIAD). Diabetes Care. 2009;32(6):971-6.

7. Pantalone KM, Wells BJ, Chagin KM, Ejzykowicz F, $\mathrm{Yu} \mathrm{C}$, Milinovich A, et al. Intensification of diabetes therapy and time until A1C goal attainment among patients with newly diagnosed type 2 diabetes who fail metformin monotherapy within a large integrated health system. Diabetes Care. 2016;39(9): 1527-34.

8. McNeill AM, Davies G, Kruger E, Kowal S, Reason T, Ejzykowicz F, et al. Ertugliflozin compared to other anti-hyperglycemic agents as monotherapy and add-on therapy in type 2 diabetes: a systematic literature review and network meta-analysis. Diabetes Ther. 2019;10(2):473-91.

9. Mearns ES, Sobieraj DM, White CM, Saulsberry WJ, Kohn CG, Doleh Y, et al. Comparative efficacy and safety of antidiabetic drug regimens added to metformin monotherapy in patients with type 2 diabetes: a network meta-analysis. PLOS ONE. 2015;10(4):e0125879.

10. Qian D, Zhang T, Zheng P, Liang Z, Wang S, Xie J, et al. Comparison of oral antidiabetic drugs as addon treatments in patients with type 2 diabetes uncontrolled on metformin: a network meta-analysis. Diabetes Ther. 2018;9(5):1945-58.

11. Higgins J GS. Cochrane Handbook for Systematic Reviews of Interventions Version 5.1.0 2011. https://training.cochrane.org/handbook/archive/ v5.1/. Accessed 6 Nov 2019.

12. Jansen JP, Fleurence R, Devine B, Itzler R, Barrett A, Hawkins $\mathrm{N}$, et al. Interpreting indirect treatment comparisons and network meta-analysis for health- care decision making: report of the ISPOR Task Force on Indirect Treatment Comparisons Good Research Practices: part 1. Value Health J Int Soc Pharmacoecon Outcomes Res. 2011;14(4):417-28.

13. Hoaglin DC, Hawkins N, Jansen JP, Scott DA, Itzler $\mathrm{R}$, Cappelleri JC, et al. Conducting indirect-treatment-comparison and network-meta-analysis studies: report of the ISPOR Task Force on Indirect Treatment Comparisons Good Research Practices: part 2. Value Health J Int Soc Pharmacoecon Outcomes Res. 2011;14(4):429-37.

14. Sterne JAC, Savovic J, Page MJ, Elbers RG, Blencowe NS, Boutron I, et al. RoB 2: a revised tool for assessing risk of bias in randomised trials. BMJ. 2019;366:14898.

15. Dias S, Welton NJ, Sutton AJ, Ades AE. NICE DSU technical support document 2: a generalised linear modelling framework for pairwise and network meta-analysis of randomised controlled trials. 2011; last updated Sept. 2016; Available from http://www. nicedsu.org.uk.

16. Dias S, Ades AE, Welton NJ, Jansen JP, Sutton AJ. Network meta-analysis for decision-making. Hoboken: Wiley; 2018.

17. Dias S, Welton NJ, Sutton AJ, Caldwell DM, Lu G, Ades AE. Evidence synthesis for decision making 4: inconsistency in networks of evidence based on randomized controlled trials. Med Decis Making. 2013;33(5):641-56.

18. Rosenstock J, Perl S, Johnsson E, Garcia-Sanchez R, Jacob S. Triple therapy with low-dose dapagliflozin plus saxagliptin versus dual therapy with each monocomponent, all added to metformin, in uncontrolled type 2 diabetes. Diabetes Obes Metab. 2019;21(9):2152-62.

19. Rosenstock J, Hansen L, Zee P, Li Y, Cook W, Hirshberg B, et al. Dual add-on therapy in type 2 diabetes poorly controlled with metformin monotherapy: a randomized double-blind trial of saxagliptin plus dapagliflozin addition versus single addition of saxagliptin or dapagliflozin to metformin. Diabetes Care. 2015;38(3):376-83.

20. Handelsman Y, Mathieu C, Del Prato S, Johnsson E, Kurlyandskaya R, Iqbal N, et al. Sustained 52-week efficacy and safety of triple therapy with dapagliflozin plus saxagliptin versus dual therapy with sitagliptin added to metformin in patients with uncontrolled type 2 diabetes. Diabetes Obes Metab. 2019;21(4):883-92.

21. Muller-Wieland D, Kellerer M, Cypryk K, Skripova D, Rohwedder K, Johnsson E, et al. Efficacy and safety of dapagliflozin or dapagliflozin plus saxagliptin versus glimepiride as add-on to metformin 
in patients with type 2 diabetes. Diabetes Obes Metab. 2018;20(11):2598-607.

22. DeFronzo RA, Lewin A, Patel S, Liu D, Kaste R, Woerle HJ, et al. Combination of empagliflozin and linagliptin as second-line therapy in subjects with type 2 diabetes inadequately controlled on metformin. Diabetes Care. 2015;38(3):384-93.

23. Pratley RE, Eldor R, Raji A, Golm G, Huyck SB, Qiu $Y$, et al. Ertugliflozin plus sitagliptin versus either individual agent over 52 weeks in patients with type 2 diabetes mellitus inadequately controlled with metformin: The VERTIS FACTORIAL randomized trial. Diabetes Obes Metab. 2018;20(5): 1111-20.

24. Ji L, Liu Y, Miao H, Xie Y, Yang M, Wang W, et al. Safety and efficacy of ertugliflozin in Asian patients with type 2 diabetes mellitus inadequately controlled with metformin monotherapy: VERTIS Asia. Diabetes Obes Metab. 2019;21(6):1474-82.

25. Yang W, Han P, Min KW, Wang B, Mansfield T, T'Joen C, et al. Efficacy and safety of dapagliflozin in Asian patients with type 2 diabetes after metformin failure: a randomized controlled trial. J Diabetes. 2016;8(6):796-808.

26. Yang W, Guan Y, Shentu Y, Li Z, Johnson-Levonas AO, Engel SS, et al. The addition of sitagliptin to ongoing metformin therapy significantly improves glycemic control in Chinese patients with type 2 diabetes. J Diabetes. 2012;4(3):227-37.

27. Yang W, Pan CY, Tou C, Zhao J, Gause-Nilsson I. Efficacy and safety of saxagliptin added to metformin in Asian people with type 2 diabetes mellitus: a randomized controlled trial. Diabetes Res Clin Pract. 2011;94(2):217-24.

28. Wang W, Yang J, Yang G, Gong Y, Patel S, Zhang C, et al. Efficacy and safety of linagliptin in Asian patients with type 2 diabetes mellitus inadequately controlled by metformin: A multinational 24-week, randomized clinical trial. J Diabetes. 2016;8(2): 229-37.

29. Pan C, Xing X, Han P, Zheng S, Ma J, Liu J, et al. Efficacy and tolerability of vildagliptin as add-on therapy to metformin in Chinese patients with type 2 diabetes mellitus. Diabetes Obes Metab. 2012;14(8):737-44.

30. Rodbard HW, Rosenstock J, Canani LH, Deerochanawong C, Gumprecht J, Lindberg SO, et al. Oral semaglutide versus empagliflozin in patients with type 2 diabetes uncontrolled on metformin: the PIONEER 2 trial. Diabetes Care. 2019;42(12): 2272-81.
31. Cahn A, Cefalu WT. Clinical considerations for use of initial combination therapy in type 2 diabetes. Diabetes Care. 2016;39(Suppl 2):S137-45.

32. Eckel RH, Kahn SE, Ferrannini E, Goldfine AB, Nathan DM, Schwartz MW, et al. Obesity and type 2 diabetes: what can be unified and what needs to be individualized? J Clin Endocrinol Metab. 2011;96(6):1654-63.

33. Baker WL, Smyth LR, Riche DM, Bourret EM, Chamberlin KW, White WB. Effects of sodiumglucose co-transporter 2 inhibitors on blood pressure: a systematic review and meta-analysis. J Am Soc Hypertens. 2014;8(4):262-75.e9.

34. Pawaskar M, Bilir SP, Kowal S, Gonzalez C, Rajpathak S, Davies G. Cost-effectiveness of DPP-4 inhibitor and SGLT2 inhibitor combination therapy for type 2 diabetes. Am J Manag Care. 2019;25(5): 231-8.

35. Lavalle-Gonzalez FJ, Januszewicz A, Davidson J, Tong C, Qiu R, Canovatchel W, et al. Efficacy and safety of canagliflozin compared with placebo and sitagliptin in patients with type 2 diabetes on background metformin monotherapy: a randomised trial. Diabetologia. 2013;56(12):2582-92.

36. Bolinder J, Ljunggren O, Kullberg J, Johansson L, Wilding J, Langkilde AM, et al. Effects of dapagliflozin on body weight, total fat mass, and regional adipose tissue distribution in patients with type 2 diabetes mellitus with inadequate glycemic control on metformin. J Clin Endocrinol Metab. 2012;97(3):1020-31.

37. Bailey CJ, Gross JL, Pieters A, Bastien A, List JF. Effect of dapagliflozin in patients with type 2 diabetes who have inadequate glycaemic control with metformin: a randomised, double-blind, placebocontrolled trial. Lancet. 2010;375(9733):2223-33.

38. Haring HU, Merker L, Seewaldt-Becker E, Weimer M, Meinicke T, Broedl UC, et al. Empagliflozin as add-on to metformin in patients with type 2 diabetes: a 24-week, randomized, double-blind, placebo-controlled trial. Diabetes Care. 2014;37(6): 1650-9.

39. Rosenstock J, Frias J, Pall D, Charbonnel B, Pascu R, Saur D, et al. Effect of ertugliflozin on glucose control, body weight, blood pressure and bone density in type 2 diabetes mellitus inadequately controlled on metformin monotherapy (VERTIS MET). Diabetes Obes Metab. 2018;20(3):520-9.

40. Hollander P, Liu J, Hill J, Johnson J, Jiang ZW, Golm $\mathrm{G}$, et al. Ertugliflozin compared with glimepiride in patients with type 2 diabetes mellitus inadequately controlled on metformin: the VERTIS SU randomized study. Diabetes Ther. 2018;9(1):193-207. 
41. Nauck MA, Ellis GC, Fleck PR, Wilson CA, Mekki Q. Efficacy and safety of adding the dipeptidyl peptidase-4 inhibitor alogliptin to metformin therapy in patients with type 2 diabetes inadequately controlled with metformin monotherapy: a multicentre, randomised, double-blind, placebo-controlled study. Int J Clin Pract. 2009;63(1):46-55.

42. Taskinen MR, Rosenstock J, Tamminen I, Kubiak R, Patel S, Dugi KA, et al. Safety and efficacy of linagliptin as add-on therapy to metformin in patients with type 2 diabetes: a randomized, double-blind, placebo-controlled study. Diabetes Obes Metab. 2011;13(1):65-74.

43. DeFronzo RA, Hissa MN, Garber AJ, Luiz Gross J, Yuyan Duan R, Ravichandran S, et al. The efficacy and safety of saxagliptin when added to metformin therapy in patients with inadequately controlled type 2 diabetes with metformin alone. Diabetes Care. 2009;32(9):1649-55.
44. Charbonnel B, Karasik A, Liu J, Wu M, Meininger G. Efficacy and safety of the dipeptidyl peptidase-4 inhibitor sitagliptin added to ongoing metformin therapy in patients with type 2 diabetes inadequately controlled with metformin alone. Diabetes Care. 2006;29(12):2638-43.

45. Gadde KM, Vetter ML, Iqbal N, Hardy E, Ohman P. Efficacy and safety of autoinjected exenatide onceweekly suspension versus sitagliptin or placebo with metformin in patients with type 2 diabetes: the DURATION-NEO-2 randomized clinical study. Diabetes Obes Metab. 2017;19(7):979-88.

46. Raz I, Chen Y, Wu M, Hussain S, Kaufman KD, Amatruda JM, et al. Efficacy and safety of sitagliptin added to ongoing metformin therapy in patients with type 2 diabetes. Curr Med Res Opin. 2008;24(2):537-50. 